\title{
Aspects of transition cow metabolomics-Part I: Effects of a metaphylactic butaphosphan and cyanocobalamin treatment on the metabolome in liver, blood, and urine in cows with different liver metabotypes
}

\author{
M. Schären, ${ }^{1 *} †$ T. Snedec, ${ }^{1 *}$ B. Riefke, ${ }^{2}$ M. Slopianka, ${ }^{2} \ddagger$ M. Keck, ${ }^{2}$ S. Gruendemann, ${ }^{2}$ J. Wichard, ${ }^{2}$ N. Brunner, ${ }^{3}$ \\ S. Klein, ${ }^{3}$ K. B. Theinert, ${ }^{1}$ F. Pietsch, ${ }^{1}$ A. Leonhardt, ${ }^{1}$ S. Theile, ${ }^{1}$ F. Rachidi, ${ }^{1}$ A. Kaiser, ${ }^{1}$ G. Köller, ${ }^{4}$ E. Bannert, ${ }^{1}$ \\ J. Spilke, ${ }^{5}$ and A. Starke ${ }^{1}$ \\ ${ }^{1}$ Clinic for Ruminants and Swine, Faculty of Veterinary Medicine, University of Leipzig, An den Tierkliniken 11, 04103 Leipzig, Germany \\ 2Bayer AG, Pharmaceuticals, Research and Development, 13342 Berlin, Germany \\ ${ }^{3}$ Bayer Animal Health GmbH, 51373 Leverkusen, Germany \\ ${ }^{4}$ Laboratory of Large Animal Clinics, Faculty of Veterinary Medicine, University of Leipzig, An den Tierkliniken 11, 04103 Leipzig, Germany \\ ${ }^{5}$ Biometrics and Informatics in Agriculture Group, Institute of Agricultural and Nutritional Sciences, Martin-Luther University, Halle-Wittenberg, \\ Karl-Freiherr-von-Fritsch-Str. 4, 06108 Halle (Saale), Germany
}

\section{ABSTRACT}

Dairy cows in modern production systems are at risk to develop metabolic disorders during the transition period. Reasons for individual differences in susceptibility, as well as the underlying pathomechanisms, are still only partially understood. The development of metaphylactic treatment protocols is needed. In this context, an on-farm prospective 3-fold blinded randomized study involving 80 German Holstein cows was performed throughout $1 \mathrm{yr}$. The trial involved a thorough recording of the production and clinical traits, clinical chemistry, and liver biopsies and blood and urine sampling at d 14 (mean: $12 \mathrm{~d}$, range: 1-26 d) antepartum (AP), and d 7 (7, 4-13) and $28(28,23-34)$ postpartum (PP) for metabolomics analyses. Two groups received a treatment with butaphosphan and cyanocobalamin (BCC) at either the dosage recommended by the manufacturer or the double dosage $(5$ or $10 \mathrm{~mL} / 100 \mathrm{~kg}$ of body weight $10 \%$ butaphosphan and $0.005 \%$ cyanocobalamin (Catosal, Bayer Animal Health), $\mathrm{n}=20$ in each group, parity: $4.2 \pm 2.0$ and $3.4 \pm 1.3$, respectively (mean \pm $\mathrm{SD})]$ and one group a placebo treatment $(\mathrm{NaCl} 0.9 \%$, $\mathrm{n}=40$, parity: $4.0 \pm 1.9)$. The animals were treated at 6 time points $(7,6$, and $5 \mathrm{~d}$ AP, and 1,2 , and $3 \mathrm{~d}$ $\mathrm{PP})$ via intravenous injection. Mass spectroscopy-based targeted metabolomics analysis of blood plasma and liver samples were performed using the AbsoluteIDQ p180 kit (Biocrates Life Sciences), whereas the urine samples were analyzed by nuclear magnetic resonance

Received June 9, 2020.

Accepted March 16, 2021.

*These authors contributed equally to this work.

†Corresponding author: melanie.schaeren@uni-leipzig.de

$\ddagger$ Current address: BASF Metabolome Solutions GmbH, 10589 Berlin, Germany. spectroscopy. Statistical analysis was performed using multivariate [partial least squares discriminant analysis (PLS-DA)] and univariate methods (linear mixed model). Multivariate data analysis (PLS-DA plots) of the liver metabolome revealed 3 different metabotypes $(\mathrm{A}=$ medium, $\mathrm{B}=$ minor, $\mathrm{C}=$ large alterations in liver metabolome profile between $\mathrm{AP}$ and $\mathrm{PP}$ status). Metabotype B animals were characterized by higher PP lipomobilization (stronger PP body condition decrease and higher blood bilirubin, fatty acids, gamma-glutamyltransferase, and triglyceride levels) and a higher occurrence of transition cow diseases, compared with the animals in metabotype C. Analysis of the feeding data showed that the period of metabotype B animals (calving in a distinct time frame) was characterized by a decreased grass silage quality. The PP liver metabolome of the metabotype $\mathrm{C}$ animals was characterized by higher concentrations of AA, acylcarnitines, lysoPC and sphingomyelins compared with metabotype B. For the metaphylactic treatment with $\mathrm{BCC}$ a dosedependent effect was confirmed, differing between the metabotypes. In all matrices and metabotypes at various time points significant treatment effects were observed, with different profiles in clinical chemistry and as well in metabolomics data. The most clear-cut treatment effect was observed in metabotype B in the liver at $7 \mathrm{~d}$ PP, characterized by an increase in several acylcarnitines and phosphatidylcholines, indicating a more efficient influx and oxidation of fatty acids in mitochondria and thereby an increase in energy supply and more efficient triglyceride export in the liver. The results from the liver metabolomics analysis support the application of an indication-based metaphylactic treatment with BCC.

Key words: peripartum period, liver biopsy, fatty liver, postpartum diseases 


\section{INTRODUCTION}

The physiological postpartum (PP) negative energy balance (NEB) is increased substantially in highyielding dairy cows, demanding a highly professional management from a nutritional and husbandry point of view. If the energy and nutrient requirements are not met, different clinical sequelae may occur, summarized under the multifactorial disease complex "transition cow diseases" (Ingvartsen, 2006; Mulligan et al., 2006; Mulligan and Doherty, 2008). In this context, the liver, as the main metabolic organ, holds a key function. During the NEB, especially in the first few days after calving, large amounts of body tissue (e.g., fat reserves and muscle) are mobilized and their components metabolized by the liver to directly convertible energy sources, such as ketone bodies and glucose (Drackley et al., 2001; Roche et al., 2013). The conversion of the circulating fatty acids (FA) forms a metabolic bottle neck (Bobe et al., 2004). If the hepatic uptake of lipids exceeds the oxidation and secretion, triacylglycerols (TAG) accumulate in the liver (Drackley et al., 2001; Bobe et al., 2004). A certain degree of hepatic lipidosis after calving is regarded as physiological and reversible (Reid and Collins, 1980; Grummer, 1993; Drackley et al., 2001). If, however, the influx of FA into the liver surpasses its metabolic capacity, overall liver function is hampered long term, and the animal may succumb to fatty liver syndrome (Bobe et al., 2004; Drackley et al., 2005).

Many studies have been published on different compounds to positively influence the energy metabolism and the nutritional status of the transition dairy cow, and several of the investigated products and metaphylactic treatment protocols have found their way into practical application (e.g., glycogenic precursors such as propylene glycol, ionophores, rumen-protected methionine and choline, CLA; Grummer, 2008; Mann et al., 2019; Manning, 2019). A compound mixture with a long worldwide history in practical application in this context is the injectable combination of butaphosphan and cyanocobalamin (BCC, vitamin $\mathrm{B}_{12}$ ), commercially available as Catosal (Bayer Animal Health $\mathrm{GmbH}$, Leverkusen, Germany; Kreipe et al., 2011).

The effect of a BCC supplementation has been studied in various settings. Taken together the studies showed a dose-dependent beneficial effect on the metabolism of periparturient dairy cows, when applied in multiple i.m. or i.v. injections. The observed effects included a reduction of morbidity (Sommer et al., 1971) and subclinical and clinical ketosis (Rollin et al., 2010; Pereira et al., 2013; Gordon et al., 2017b), increased fertility (Palmer, 1980; Şahal et al., 2017), higher milk production and total solid yields (Girard and Matte, 2005; Cuteri et al., 2008; Preynat et al., 2009), faster convalescence after left abomasal displacement (LDA) operation (Fürll et al., 2006; Lohr et al., 2006) and a faster reduction of SCC in clinical mastitis (Tabeleão et al., 2016). These clinical beneficial effects can be ascribed to the compounds' positive interference with adaptational mechanisms of glucose metabolism (increasing rate of propionate utilization for gluconeogenesis), and increasing glucose availability (Fürll et al., 2010; Tabeleão et al., 2017). The exact pharmacomechanisms are however not fully elucidated (Kreipe et al., 2011; Nuber et al., 2016).

The aim of the study presented was therefore to study the pathomechanisms in transition cow liver metabolism by: (1) characterizing changes in liver, blood, and urine metabolome in transition dairy cows, (2) identifying possible liver metabotypes in a follow-up analysis, and (3) extrapolate and interrelate these metabotypes with production and clinical traits, clinical chemistry, and liver histopathology, and to further elucidate the pharmaco-mechanisms of a metaphylactic treatment with BCC.

In this first part, the study design, the identification of the metabotypes and their differences on production and clinical level (clinical traits and chemistry), as well as the effects of a metaphylactic treatment with $\mathrm{BCC}$ on the clinical and metabolomic level are described. Part II (Pietsch et al., 2021) illustrates the liver histopathological alterations across the transition period and their relation to the metabotypes and which changes were affected by a metaphylactic BCC treatment. In Part III (Schären et al., 2021), a detailed elaboration on the alterations of liver and blood metabolomic profiles in the different metabotypes is given and (patho)physiological relevancies are discussed.

\section{MATERIALS AND METHODS}

An on-farm randomized, prospective, 3-fold blinded study was performed on a 660-cow dairy in Saxony (Germany), between November 23, 2015, and December 3,2016 . The experiment was carried out in accordance with the German Animal Welfare Act approved by the LDS (Landesdirektion Sachsen, Referat 24, Veterinärwesen und Lebensmittelüberwachung, Pharmazie, GMP Inspektorat Sachsen, Dresden, Germany) and documented with the register TVV 33/15.

\section{Animal Husbandry and Experimental Design}

The herd was characterized by a rolling average milk production of $10,747 \mathrm{~kg}$ and fat and protein content of 3.73 and $3.33 \%$, respectively [official monthly milk control report by the local state control association 
(Landeskontrollverband, Sachsen) of December 5, 2016]. The average 305-d milk production of the cows finishing a lactation (with a minimum of 250 DIM) during the trial's period was $10,718 \mathrm{~kg}(\mathrm{n}=610)$.

Management. The cows were housed in a freestall system with deep bedding boxes during lactation and deep bedded straw pack during the dry period. During the spring and summer period, the dry cows were allocated on pasture during 3 to $4 \mathrm{wk}$ after drying-off. The total dry period was 8 wk. After calving, the animals resided in a fresh-cow pen for animals milking colostrum until approximately 5 DIM, before being transferred to a second fresh-cow pen until approximately 40 DIM. Thereafter, the animals were allocated to a pen for high-yielding cows until approximately 110 DIM. Depending on their condition and milk production in the last two thirds of the lactation, they were transferred to a mid- or low-yielding group. The animals were milked 2 times/d (between 0600-0800 and 1800-2000 h) in a double 16 side-by-side milking parlor with an average walking distance of approximately 50 to $100 \mathrm{~m}$.

Feeding. The TMR-based ration included grass- and corn-silage as main components. Depending on the silage quality and DM content, the amount of concentrates and different additional components were varied (Supplemental Table S1; https://nbn-resolving.org/ urn:nbn:de:bsz:15-qucosa2-744120). The rations were calculated by a commercial nutritionist, who consulted the farm every 4 to 6 wk. Over the course of the trial, the animals were fed from 3 different corn-silage and 8 different grass silage silos. The silage qualities are indicated in Supplemental Table S2 (https://nbn-resolving .org/urn:nbn:de:bsz:15-qucosa2-744120). In Supplemental Figure S1 (https://nbn-resolving.org/urn:nbn: de:bsz:15-qucosa2-744120), the time spans throughout which the different silages were fed are illustrated for each feeding group and silage separately.

Climate. The farm was in a moderate climate zone. The daily mean temperature over the trial period was $9.5^{\circ} \mathrm{C}$ (daily maximum of $32.4^{\circ} \mathrm{C}$ and minimum of $-11.9^{\circ} \mathrm{C}$; weather station of the Deutscher Wetterdienst, station ID 853, station approximately $15 \mathrm{~km}$ distance to and $135 \mathrm{~m}$ higher than the farm) and the mean temperature-humidity index (THI) was 46.5 [maximum of 66.4 and minimum of 19.1; calculated according to Hahn, 1999; THI $=0.8 \mathrm{td}+\mathrm{RH} \times(\mathrm{td}-$ 14.4) +46.4 , where $\mathrm{td}=$ dry bulb temperature $\left({ }^{\circ} \mathrm{C}\right)$ and $\mathrm{RH}=$ relative humidity].

Experimental Animals. For the trial, 87 German Holstein cows were selected from the herd. Inclusion criteria at $14 \mathrm{~d}$ AP (calculated from the expected calving date) were: $\geq$ second lactation, pregnant, clinically healthy, no treatment $28 \mathrm{~d}$ before first sampling or persisting withdrawal period (exception: dry-off treatment), and expected dry period longer than 70 d. Seven animals were excluded during the trial due to following reasons: downer cow syndrome before calving, fetal mummification, death due to uterine prolapse, severe leg injury, temperament, misidentification (no correspondence between ear-tag and collar-number at some point during the trial) and wrong pen allocation. Furthermore, cesarean section and calving outside of physiological range $(<260$ and $>290$ d carrying calf $)$, were defined as exclusion criteria but were not encountered throughout the trial. The final number of animals included in the study was 80 . Selected cows had an average lactation number of 3.9 (range: 2-9; lactation number at calving in the trial), BCS of 2.91 [range: 2.00-3.75; BCS $14 \mathrm{~d}$ antepartum (AP) and according to 5-point scale of Edmonson et al. (1989)] and the 305d milk production in the previous lactation of 10,957 $\mathrm{kg}$ (range: 6,480-15,193 kg)]. The study included a detailed monitoring of each animal from $14 \mathrm{~d}$ AP to $49 \mathrm{~d}$ PP.

Treatments. To study the metaphylactic treatment protocol with $\mathrm{BCC}$, the following treatment groups were used: 2 groups with a Catosal treatment $(10 \%$ butaphosphan and $0.005 \%$ cyanocobalamin; Bayer Animal Health $\mathrm{GmbH}$ ) with the recommended dose (as registered in Germany) of $5 \mathrm{~mL} / 100 \mathrm{~kg}$ of $\mathrm{BW}$ (VER5, $\mathrm{n}=20$, parity: $4.2 \pm 2.0$, mean $\pm \mathrm{SD}$ ) or the double dose of $10 \mathrm{~mL} / 100 \mathrm{~kg}$ of BW (VER10, $\mathrm{n}=20$, parity: $3.4 \pm 1.3$ ), and 2 placebo groups with 5 or 10 $\mathrm{mL}$ of $\mathrm{NaCl} 0.9 \% / 100 \mathrm{~kg}$ of $\mathrm{BW}$ (for analysis, the 2 groups were merged to one control group, $\mathbf{C O N}, \mathrm{n}=$ 40, parity: $4.0 \pm 1.9$ ). The group assignment occurred randomly using a lottery procedure. The animals were treated at 6 time points: 7, 6, and $5 \mathrm{~d} \mathrm{AP}$, and 1, 2, and $3 \mathrm{~d}$ PP (Figure 1) via intravenous injection using a sterile 16-gauge, $1.80 \times 60 \mathrm{~mm}$ needle (Misawa Medical Industry Co., Ltd.). The treatment protocol was chosen on basis of the recommendation of the manufacturer (as registered in Germany) for application of the compound once daily for 3 consecutive days, and studies showing a beneficial effect of AP and repetitive treatment with BCC (Cuteri et al., 2008; Fürll et al., 2010; Rollin et al., 2010). Because of the difficulty to predict parturition, 15 cows did not receive all treatments before calving; 9 cows received none, 4 cows received 1 , and 2 received 2 treatments. Of these 15 cows, 7 belonged to the VER groups (3 received none, 2 received 1, and 2 cows received 2 treatments). The 3 -fold blinding occurred as follows: (1) the person applying the treatment and collecting the samples did not know in which group the animal belonged, (2) the person preparing the treatment for injection (filling and handing the syringe) knew only the blinded group number of the animal and the corresponding blinded 
Sampling Days

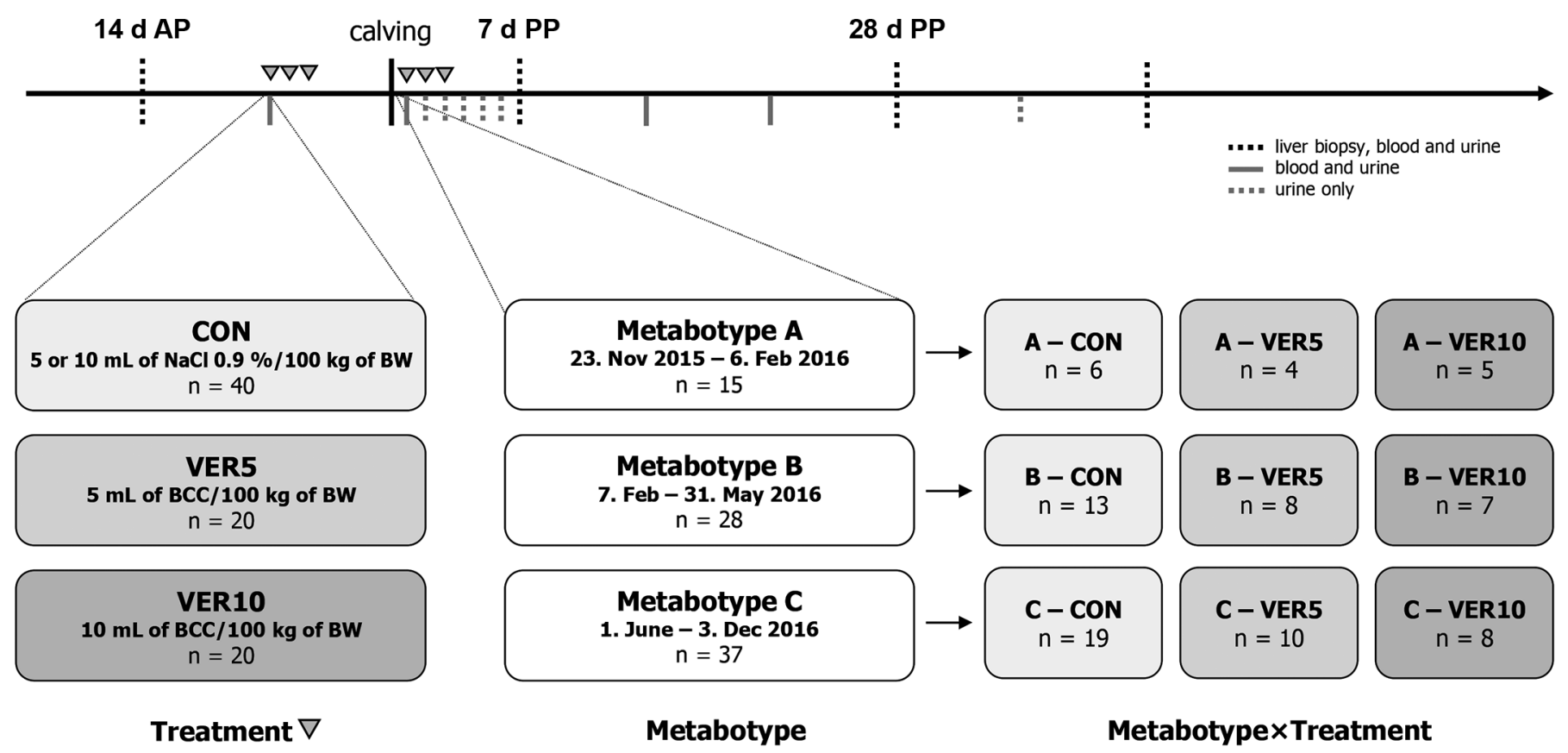

Figure 1. Study design. The animals were treated at 6 time points: 7, 6, and 5 d antepartum (AP), and 1, 2, and $3 \mathrm{~d}$ postpartum (PP, indicated by triangles), $\mathrm{BCC}=10 \%$ butaphosphan and $0.005 \%$ cyanocobalamin. For the metabolomics analysis, samples from liver biopsies, blood, and urine were collected on d $14 \mathrm{AP}$ and on d 7 and $28 \mathrm{PP}$ for later analysis.

bottles with the treatment (treatment and placebo not distinguishable due to similar viscosity and color of the product), and (3) the groups were blinded throughout the statistical analysis.

Metabotypes. Three different metabotypes were identified based on their metabolic profiles in the liver over the course of the transition period (detailed description in Results section). These groups were not part of the original trial design and were identified in the follow-up analysis. The treatment groups were almost equally distributed within the different metabotypes (Figure 1). It was further discovered that the metabotypes coincidence with the time the animals entered the study: animals calving in period A (November 23, 2015, to February 6, 2016), period B (February 7 to May 31, 2016), or period C (June 1 to December 3, 2016).

\section{Production and Clinical Traits}

Milk Yield, Components, and BCS. Milk production was recorded and milk samples were collected during the monthly official milk control. Samples were analyzed for fat and protein percentages and SCC. The BCS was recorded at 14 (mean: $12 \mathrm{~d}$, range: $1-26 \mathrm{~d}$ ) and $7 \mathrm{~d}$ AP (6, 0-21), and 7 (7, 4-10), 14 (14, 8-19), 21
(21, 14-25), 28 (28, 19-32), and $42 \mathrm{~d} \mathrm{PP}(42,39-47)$ using a 5-point scale according to Edmonson et al. (1989). Actual sampling time points varied slightly from the planned date for different practical reasons (e.g., earlier or delayed calving date, workload, or management aspects on the farm) and were accounted for in the statistical analysis (see the last section).

Clinical Traits. The clinical status of the animals was recorded throughout the trial period using a small and large standardized protocol for daily, respectively weekly, clinical examination and scoring by trained veterinarians who stayed on-site throughout the trial and supported at least twice per week by a diplomate of the European College of Bovine Health Management or a specialized buiatrician. The protocols were based on the routine clinical examination described in Dirksen et al. (2012) and treatment documentations. Briefly, they included the evaluation of the rectal body temperature, heart rate, respiratory rate, auscultation of the lung, heart, and rumen, rumen filling, stratification, contraction frequency and intensity, auscultatory percussion of the left and right abdominal wall, abdominal wall tension, lameness, skin, jugular vein, hygiene, rectal palpation and examination, fecal scoring, and the examination of the udder and the milk by well-trained 
employees of the farm. The following clinical complexes were generated for statistical analysis: rectal body temperature, respiratory, circulatory, and digestive system, ketonuria [evaluated by detection of acetoacetic acid in urine samples (Ketostix, Bayer Vital $\mathrm{GmbH}$ ), for sample collection time points, see next section], udder, genital tract (calving ease, calving injuries, retained placenta, metritis, endometritis), locomotion apparatus, claws, skin, lymph nodes, blood sampling (jugular vein) and biopsy site, and treatments [antibiotics, nonsteroidal anti-inflammatory drugs, gynecological medication and other treatments (e.g., other drugs, surgery)]. The clinical findings were assigned to the different complexes and evaluated using a scoring system (one score per complex and animal for the trials period) for general examination for different organ systems: 0 $=$ no abnormality observed; $1=$ abnormality observed once, but evaluated as not requiring treatment; $2=$ abnormality observed more than once throughout the trial, but evaluated as not requiring treatment; $3=$ abnormality entailed treatment (similar to Kretschmann et al., 2020); displaced abomasum: yes/no; treatments: $0=$ no, $1=$ yes, once/one, $2=$ yes, several treatments; clinical ketosis: yes/no; calving ease: $1=$ easy, $2=$ medium, $3=$ heavy. The clinical scores were evaluated per trait and as total sum (the higher the sum, the more the animal was clinically affected). In the statistical analysis the effect of the lactation was included to account for possible age-dependent effects. The lactation classes were defined as follows: $1=$ second lactation, $2=$ third or fourth lactation, $3=$ higher than fourth lactation (see section Data and Statistical Analysis). This aspect was excluded in the other variable groups (production, clinical chemistry, and metabolomics data) because it would have inflated the statistical models beyond the scope of this manuscript.

Sample Collection and Analysis. An overview of all the sampling time points is given in Figure 1. For the current manuscript, liver biopsies, blood and urine samples from $14 \mathrm{~d}$ AP (mean: 12, range: 1-26), and 7 (7, 4-13) and $28 \mathrm{~d}$ PP (28, 23-34) were analyzed. As for $\mathrm{BCS}$, the variation in the sampling time point was accounted for in the statistical analysis (see last section).

Liver Biopsies. At 4 time points throughout the trial, liver biopsies were collected by a trained surgeon (d 14 AP and d 7, 28, and 42 PP, Figure 1) as described in Gohlke et al. (2013). The biopsy material was gently rinsed with $\mathrm{NaCl} 0.9 \%$, and blood particles were carefully removed using gauze. Five hundred milligrams of tissue were transferred and stored in liquid nitrogen for 4 wk $\left(-196^{\circ} \mathrm{C}\right.$, storage time at the farm) and thereafter stored at $-80^{\circ} \mathrm{C}$ until analysis (analysis started in August 2017).
Blood and Urine Sampling and Analysis for Clinical Chemistry. Blood samples were collected in 10-mL serum-separating blood tubes and 10-mL blood tubes containing EDTA to prevent coagulation at d 14 and $7 \mathrm{AP}$, and $\mathrm{d} 1,7,14,21,28$, and $42 \mathrm{PP}$ (Figure 1) from the jugular vein, centrifuged $(1,100 \times g$, for $10 \mathrm{~min}$ at room temperature, Laborzentrifuge, Typ T23, VEB Zentrifugenbau Engelsdorf) within 2 h after collection, and the serum was stored at $-20{ }^{\circ} \mathrm{C}$. Serum samples were analyzed for the clinical chemistry variables panel using a Cobas c 311 system (Roche Diagnostics), including: albumin, alkaline phosphatase, alanine aminotransferase (ALT), aspartate aminotransferase (AST), BHB, bilirubin (BILI), Ca, cholesterol, creatine kinase (CK), $\mathrm{Cl}$, creatinine, gamma-glutamyltransferase (GGT), glutamyldehydrogenase, glucose, K, lactate, Mg, Na, phosphate (PHOS), TAG, total protein (TP), and urea (test kits were used according to the manufacturer's guidelines). Fatty acids were analyzed using a colorimetric-based assay (NEFA assay, Randox Laboratories Ltd.) according to the manufacturer's instructions. Glucose concentrations exhibited large unphysiological variations, which could not be explained by experimental factors, sample handling, or storage. It was therefore decided not to include glucose data from the clinical chemistry analysis in the manuscript. However, the hexoses measured in the metabolomics analysis (see below) was considered representative for blood glucose levels as glucose constituted with 90 to 95\% the largest part of hexoses (Humer et al., 2018 and authors' unpublished data). Urine samples were collected parallel to the blood samples, and additionally, daily in the first week after calving and at $\mathrm{d} 35$ PP (Figure 1). The samples were stored at $-20^{\circ} \mathrm{C}$ and analyzed for urine chloride (U-Cl) concentrations using the Cobas c 311 system.

Metabolomics Analyses. Metabolomics analyses were performed on the liver biopsy, blood plasma, and urine samples collected at d $14 \mathrm{AP}$ and $\mathrm{d} 7$ and 28 PP (Figure 1). The workflow for sample extraction, measurement, and analysis for targeted MS-based metabolomics is described in detail in the Supplemental Files (https://nbn-resolving.org/urn:nbn:de:bsz:15 -qucosa2-744120). In brief, liver samples were generated by extraction of liver tissue using a Precellys tissue homogenizer (ThermoFisher Scientific) in methanol and water. Liver extracts and plasma samples were analyzed using the AbsoluteIDQ p180 kit (Biocrates Life Sciences AG), including a set of metabolites in the following categories: acylcarnitines (40), AA (21), monosaccharides (1), glycerophospholipids (90), sphingolipids (15), and biogenic amines (21). A complete overview and abbreviations of metabolites are given in 
Supplemental Table 2A and 2B. For the MS-analysis an AB SCiex QTRAP 5500 (AB Sciex Deutschland $\mathrm{GmbH}$ ) was used. The evaluation of the analytical data was accomplished using the MetIDQ software package, which is an integral part of the Biocrates AbsoluteIDQ 180 Kit (Biocrates Lifescience AG).

For the following variables, the concentrations were lower than the lower limit of quantification: liver samples: Arg, Asp, PC ae C42:4, sphingomyelins C20:2, C22:3, and C24:1, ADMA, c4-OH-Pro, DOPA, Kyn, Met-SO, Nitro-Tyr, PEA, putrescine, and sarcosine. Liver and blood: spermidine and spermine. In these cases, the values and accuracy of the signal was checked if the value could be included with confidence in the analysis. Metabolite levels below the limit of detection were treated as missing value. Sixteen out of the 240 liver samples were lost due to errors in sample preparation, derivatization and improperly working internal standard, and were declared as missing. This affected 2,9 , and 1 sample(s) in the CON group at d $14 \mathrm{AP}$ and 7 and $28 \mathrm{PP}$, respectively, and 1 and 3 samples in the VER10 and VER5 group at d 7 PP.

The urine samples were analyzed by nuclear magnetic resonance (NMR)-spectroscopy. However, no further annotation of the "buckets" to the corresponding metabolites was performed due to limited resources. A detailed description of the sample preparation and the analysis is given in the Supplemental Files of this manuscript.

\section{Data and Statistical Analysis}

Milk Production. For the statistical analysis of the milk yield and content data, a set of comparable animals from the herd $(\mathrm{n}=206$, HERD, criteria: calving in the same period, same inclusion/exclusion criteria) were included in the analysis to appropriately account for test-day effects. Energy-corrected milk yield $(\mathrm{kg} / \mathrm{d})$ was calculated as follows: $\mathrm{ECM}=$ milk yield $(\mathrm{kg} / \mathrm{d}) \times$ $\{[1.05+(0.38 \times$ fat $\%)+(0.21 \times$ protein $\%)] / 3.28\}$ according to the Society of Nutrition Physiology (2001). For statistical analysis, the SCC were transformed into SCS according to international standards (Reents et al., 1995), using the following logarithmic transformation: $\mathrm{SCS}=\log _{2}(\mathrm{SCC} / 100,000.0)+3$.

The data were analyzed using a fixed regression testday model [using PROC MIXED in SAS 9.4 (SAS Institute)] as described in detail by Mielenz et al. (2006). For fat, protein, and SCS, the lactation model by Ali and Schaeffer (1987) was superior, compared with fractional second-order models by Akaike information criterion (AICC). For milk yield and ECM, a fractional second-order model was used.
The fractional second-order approach required 3 covariables for the description of the lactation curve $x_{0}(\mathrm{t})=1.0 ; x_{1}(t)=t^{-0.5} ; x_{2}(t)=t$, the Ali and Schaeffer (1987) approach required 5 covariables: $x_{0}(t)=$ $1.0 ; x_{1}(t)=t ; x_{2}(t)=t^{2} ; x_{3}(t)=\log (1 / t) ;$ and $x_{4}(t)=$ $[\log (1 / t)]^{2}$ with the standardized DIM $t=t_{i j k} / t_{\max }\left(t_{i j k}=\right.$ DIM of study animal $k$ in treatment group $i$ on test day $j$ and $t_{\max }=$ maximum of DIM, here 350$)$. The record of study animal $k$ in treatment group $i$ on test day $j$ was modeled as follows:

$$
y_{i j k}(t)=\sum_{r=0}^{b} \beta_{i r} \times x_{r}(t)+T D_{j}+a_{k}+e_{i j k},
$$

where $T D_{j}$ is the fixed effect of test day $j(j=1, \ldots$, 11), $\beta_{i 0}$ to $\beta_{i b}$ the fixed regression coefficients of treatment group $i\left(i=\mathrm{CON}\right.$, VER5, VER10, HERD), $a_{k}$ the random effect of study animal $k$ and $e_{i j k}$ the random residual effect. The covariance of the residual effects within study animal was modeled by the TOEPLITZ(2) function. Results are presented as least squares means (LSM) curves per DIM as LSM per lactation period. For comparison of treatment groups per lactation period, the Tukey test was applied. For calculation of the degrees of freedom we used the Kenward and Roger approximation (Kenward and Roger, 1997, 2009).

To examine the influence of the metabotype on milk production and content a separate analysis for the first 100 DIM was conducted. Here for ECM, a valid model could be calculated only from 8 DIM onwards. An analysis beyond 100 DIM was not possible, due to uneven distribution of DIM per metabotype. This evaluation model contains no separate test-day effects. However, the effects of the metabotypes are a mean expression of the test-day effects in the respective period.

The record of study animal $k$ in treatment group $i$ and metabotype $j$ was modeled as follows:

$$
y_{i j k}(t)=\sum_{r=0}^{b} \beta_{i j r} \times x_{r}(t)+a_{k}+e_{i j k}
$$

where $\beta_{i j 0}$ to $\beta_{i j b}$ are the fixed regression coefficients of treatment group $i(i=\mathrm{CON}$, VER5, VER10, HERD) in metabotype $j(j=1, \ldots, 3), a_{k}$ the random effect of study animal $k$ and $e_{i j k}$ the random residual effect. Here, covariance matrix of the residual effects had a simple diagonal structure. The preference for this structure in the model selection was especially due to the short lactation period $(100 \mathrm{~d})$ and the associated low number of observations within animal. Throughout this part of the analysis, the fractional second-order approach proved to be beneficial. Results are presented in the same form as in the analysis described above. 
Clinical Traits. For analyzing the ordinal variable clinical scores, the cumulative logit model based on the threshold concept is used (McCulloch and Searle, 2001). Let $Y_{i j k}$ be the ordinal response (with $r$ categories) of treatment group $i$, metabotype $j$ and lactation class $k$. Further let $Z_{i j k}$ be the underlying continuous latent variable and $\theta_{n}$ cutpoints (thresholds with $\mathrm{n}=1, \ldots$, $r-1)$. Then the cumulative logit model is given by

$$
\operatorname{logit}\left[P\left(Y_{i j k} \leq n\right)\right]=\operatorname{logit}\left[P\left(Z_{i j k} \leq \theta_{n}\right)\right]=\theta_{n}-\eta_{i j k},
$$

with $\eta_{i j k}=\mu+G_{i}+S G_{j}+L C_{k}$, where $\eta_{i j k}$ is the linear predictor, $G_{i}=$ treatment group effect (fix; $i=1,2,3$ where $1=\mathrm{CON}, 2=\mathrm{VER} 5$, and $3=\mathrm{VER} 10), S G_{j}=$ metabotype effect (fix; $j=1,2,3$, where $1=\mathrm{A}, 2=\mathrm{B}$ and $3=\mathrm{C}$ ), $L C_{k}=$ lactation class effect (fix; $k=1,2$, and 3$)$.

For estimation of the model parameter the MaximumLikelihood method implemented in PROC GLIMMIX of SAS 9.4 was used. The implementation provides F-test (related to the effects in the linear predictor), cumulative probabilities and odds ratio.

BCS, Clinical Chemistry, Metabolomics Data and Sum of Clinical Scores. Statistical analysis of the clinical chemistry and metabolomics data was carried out by the following linear mixed model:

$$
\begin{aligned}
Y_{i j k l}\left(\mathrm{x}_{i j k l}\right)=\mu & +G_{i}+T_{j}+S G_{k}+(G \times T)_{i j} \\
+(G \times S G)_{i k} & +(T \times S G)_{j k}+(G \times T \times S G)_{i j k} \\
& +\mathrm{b}_{1} \times \mathrm{x}_{i j k l}+e_{i j k l},
\end{aligned}
$$

where $G_{i}=$ fixed treatment group $(i=$ CON, VER5, VER10 $), T_{j}=$ fixed sampling day $(j=14 \mathrm{AP}$ and 7 and $28 \mathrm{PP}), S G_{k}=$ fixed metabotype $(k=\mathrm{A}, \mathrm{B}$, and $\mathrm{C}$, their fixed interactions), $e_{i j k l}=$ random error and $l$ random study animal $(l=1, \ldots, 80)$. The difference between effective and planned sampling time point $\left(\mathrm{x}_{i j k l}\right)$ was accounted for by the linear regression coefficient $b_{1}$.

For the vector $\mathbf{e}_{i j k l}=\left(e_{i 1 k l}, e_{i 2 k l}, e_{i 3 k l}\right)$ of the random error effects within animal $(l)$ it applies $\mathbf{e}_{i j k l} \sim N(0, \mathbf{R})$, where $\mathbf{R}$ is a $(3 \times 3)$ variance-covariance matrix [corresponding to the 3 sampling time points, in case of BCS $\mathbf{R}$ has the dimension $(7 \times 7)$, due to 7 sampling time points], whereby the correlation of the residual effects within each animal is accounted for. Best fitting structures for $\mathbf{R}$ were tested using the Akaike information criterion for a finite sample size using following candidate structures: VC, CS, TOEP, UN. As covariance structure either "unstructured (UN)" or "variance components (VC)" was used.

For the sum of clinical scores, following model was implemented:

$$
\begin{aligned}
Y_{i j k l}= & \mu+G_{i}+S G_{j}+L C_{k}+(G \times S G)_{i j} \\
& +(G \times L C)_{i k}+(S G \times L C)_{j k} \\
& +(G \times S G \times L C)_{i j k}+e_{i j k l .}
\end{aligned}
$$

The same abbreviations were valid as in the model above, but a lactation class effect $L C$ was considered $\left[L C_{k}=\right.$ lactation class effect (fix; $k=1,2$ and 3 )]. In contrast to clinical traits and BCS, we did not have to take into account any repeated measurements per animal. Thus, $\mathbf{R}$ has a simple diagonal structure. For F-test of fixed effects and pairwise comparison of LSM using Tukey test multiple testing and the approximation for the degrees of freedom as described in Kenward and Roger (1997, 2009) was used.

Evaluation of the linear mixed model was performed using PROC MIXED as described above (SAS 9.4, SAS Institute). The distribution of the residuals was checked by Shaphiro-Wilk test (PROC UNIVARIATE, SAS Institute). BCS and clinical chemistry variables albumin, alkaline phosphatase, ALT, AST, BHB, BILI, $\mathrm{Ca}$, cholesterol, $\mathrm{CK}, \mathrm{Cl}$, creatinine, GGT, glutamyldehydrogenase, lactate, Na, TAG, TP, FA, UREA, and $\mathrm{U}-\mathrm{Cl}$ were log-transformed before statistical analysis to attain normal distribution of the residuals. For these traits the estimated LSMeans, SE as well as confidence limits in the transformed scale were retransformed and reported. Results were considered significant at $P<$ 0.05 and a trend declared at $0.05<P<0.10$.

Multivariate Data Analysis. Multivariate data analysis was performed on liver, blood and urine metabolomics data using the software package SIMCA (version 15 and 16, Umetrics), which included principal component analysis and partial least squares discriminant analysis (PLS-DA). The quantitative MS and clinical chemistry data were scaled to unit variance. For the urine metabolomics samples, the bucketed NMR-data were pareto-scaled and PLS-DA models were used for the metabotypes and treatment effects, without annotation of specific metabolites (see above). Furthermore, driver variables were selected for the liver and blood metabolomics data from the respective loadings plots of the PLS-DA models (indicated in the permutation plots in the Supplemental Files). Variables located between -0.5 and 0.5 of the component axis $(\mathrm{x})$ were excluded for the next model to reduce noise and thus increase correlation and prediction. Permutation test were performed to validate the models and test for over-fitting as described in Sun et al. (2014). In this manuscript, only valid models were depicted, and the respective permutations tests added in the Supplemental Files. After unsuccessfully testing for valid models differentiating between the treatment groups VER5, 
VER10, and CON, the groups VER5 and VER10 were combined to one group (VER) for further analysis, delivering valid models (see Results section).

\section{RESULTS}

\section{The Identification of the Metabotypes}

The multivariate data analysis of the 3 different matrices (liver, blood, urine) showed a clear time effect: the
3 different sampling points cluster distinctively (Figure $2 \mathrm{~A}-\mathrm{C}$ ), indicating large metabolic alterations over the course of the 6 peripartum weeks. However, in the plot showing the liver metabolomics data, a differentiation of the PP samples into 2 different larger clusters along principal component t(1) was observed (Figure 2C).

When analyzing the trajectories of the 3 samples on the PLS-DA plots in the liver metabolomics data of each animal (14 d AP; 7 and $28 \mathrm{~d}$ PP) 3 different metabotypes were identified (Figure 2C1-C3). Especially
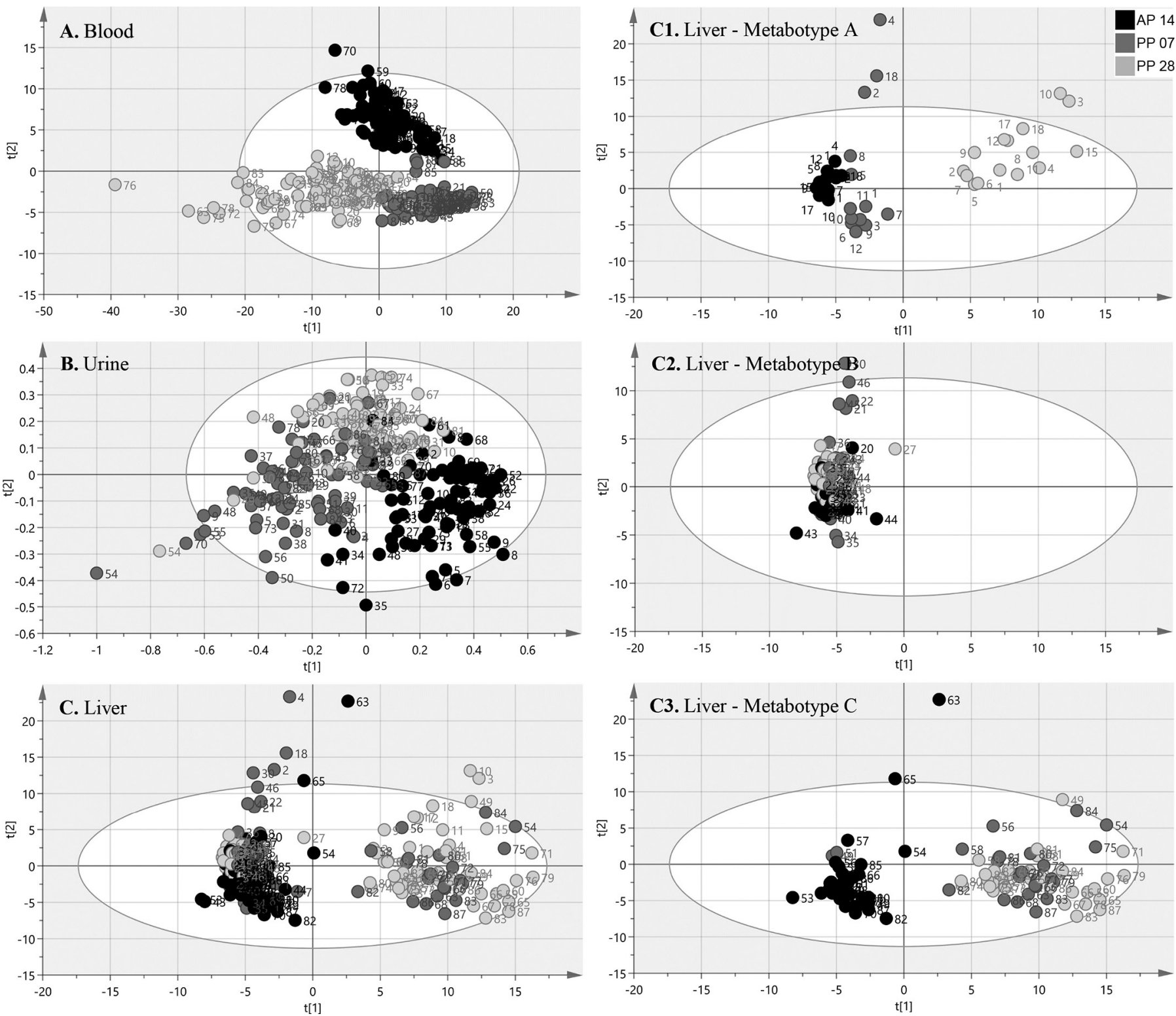

Figure 2. Partial least squares discriminant analysis (PLS-DA) models of blood (A), urine (B), and liver (C) metabolome. Gray scale of dots indicates the sampling day (14 d antepartum, and 7 and $28 \mathrm{~d}$ postpartum), according to the legend. By analyzing individual trajectories along the sampling days in the liver, 3 different metabotypes were identified (C1-C3) coinciding with the time the animals entered the study: metabotype A: animal no. 1-15, 17, and 18, calving between November 23, 2015, and February 6, 2016 (n = 15), metabotype B: animal no. 16, 19-48, calving between February 7 and May 31, $2016(\mathrm{n}=28)$, metabotype C: animal no. 49-87, calving between June 1 and December 3, 2016 $(\mathrm{n}=37)$. Numbers beside dots indicate specific animal numbers. $\mathrm{t}[1]$ and $\mathrm{t}[2]=$ principal components of the PLS-DA model. 

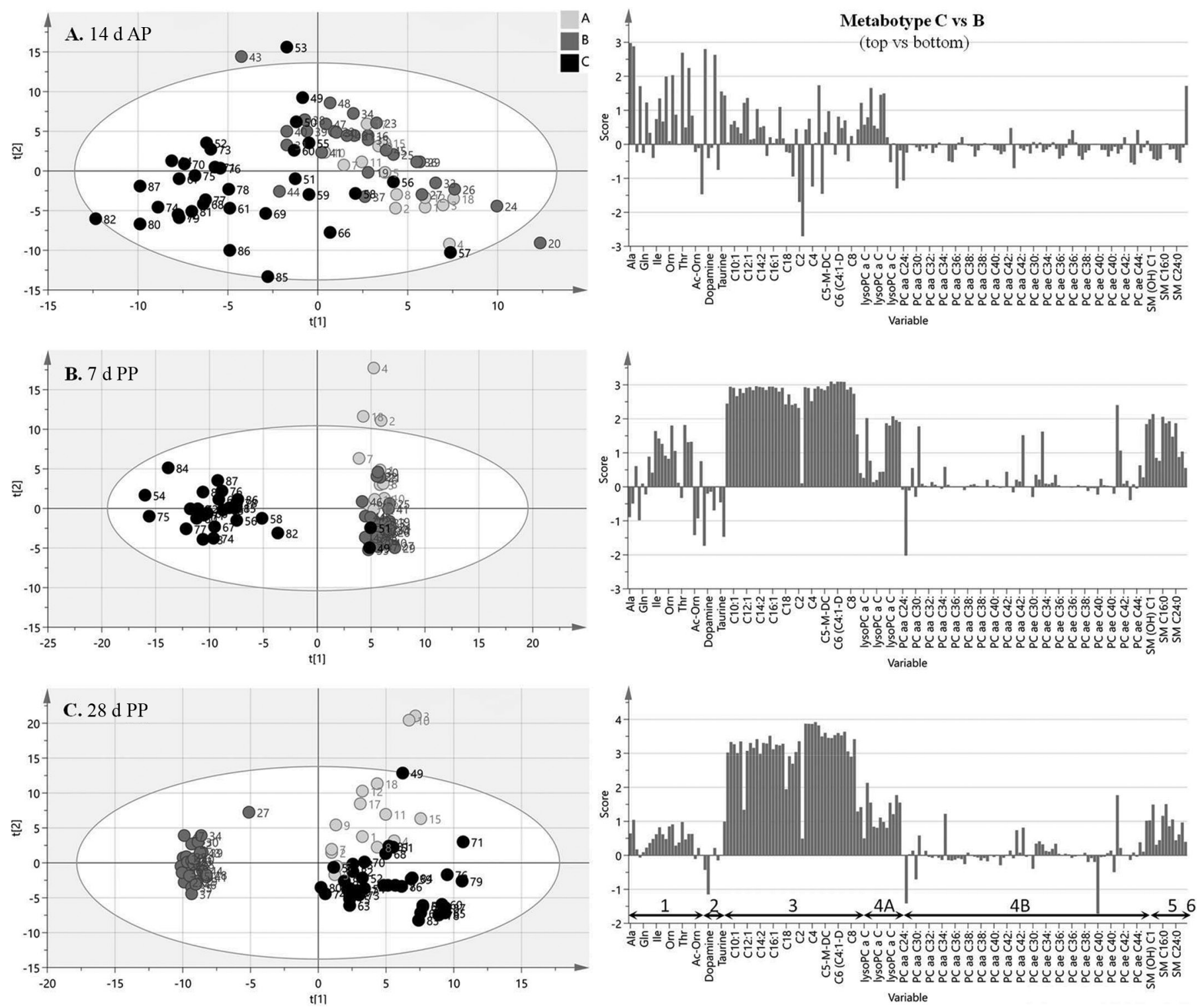

Figure 3. Partial least squares discriminant analysis (PLS-DA) models (left) and respective contributions plots (right) of the liver metabolome at the different sampling days. Gray scale of dots indicates the metabotype A, B, and C according to the legend. Numbers beside dots indicate the trial specific animal number. The contribution plots show the whole panel of metabolites analyzed; locations of respective metabolite groups are indicated with arrows and numbers: 1. AA, 2. biogenic amines, 3. acylcarnitines, 4. glycerophospholipids, 4A. lysophophatidylcholines, 4B. phosphatidylcholines, 5. sphingolipids: sphingomyelines, 6 . hexoses. The vertical bars indicate the weighted difference between the data of the point and the average of the model in units of standard deviations. $t[1]$ and $t[2]=$ principal components of the PLS-DA model.

metabotype $\mathrm{B}$ and $\mathrm{C}$ exhibit 2 distinct patterns, with the PP state being either barely different (metabotype $\mathrm{B}$, Figure $2 \mathrm{C} 2$ ) or very different (metabotype C; Figure 2C3) from the AP state. Further analysis of the data set showed that the grouping of the animals depended on their time entering the study (as described in the Material and Methods part).

The comparison of the PP metabolite profiles of the metabotypes $\mathrm{B}$ and $\mathrm{C}$ revealed higher concentrations in a whole range of metabolites in metabotype $\mathrm{C}$. The main affected clusters include acylcarnitines, lysoPC and sphingomyelins (Figure 3B and $\mathrm{C}$; contribution plots presented in a higher resolution in Supplemental Figure $7 \mathrm{~A}-\mathrm{C})$.

The 3 metabotypes $\mathrm{A}, \mathrm{B}$, and $\mathrm{C}$ could also be identified in blood and urine samples using respective PLS-DA models. Also, in these matrices, the 2 metabotypes B and C already differed AP. Compared 

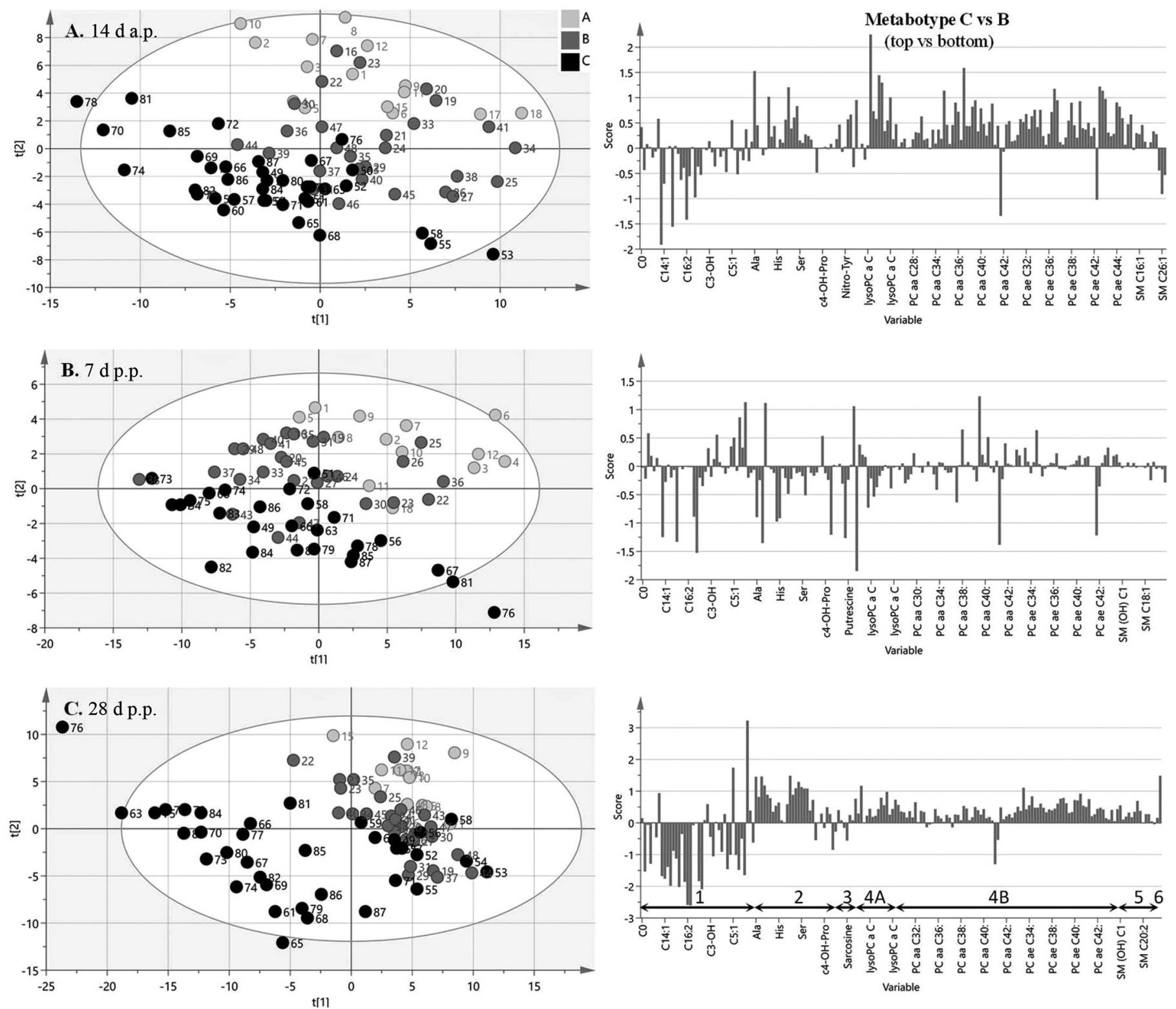

Figure 4. Partial least squares discriminant analysis (PLS-DA) models (left) and respective contributions plots (right) of the blood metabolome at the different sampling days. Gray scale of dots indicates the metabotype A, B, and C according to the legend. Numbers beside dots indicate the trial specific animal number. The contribution plots show the whole panel of metabolites analyzed; locations of respective metabolite groups are indicated with arrows and numbers: 1. acylcarnitines, 2. AA, 3. biogenic amines, 4. glycerophospholipids, 4A. lysophophatidylcholines, 4B. phosphatidylcholines, 5 . sphingolipids: sphingomyelines, 6 . hexoses. The vertical bars indicate the weighted difference between the data of the point and the average of the model in units of standard deviations. $t[1]$ and $t[2]=$ principal components of the PLS-DA model.

with the liver, the contribution plots revealed a different pattern in the blood samples (Figure 4). At 7 $\mathrm{d}$ PP the comparison of the 2 metabotypes $\mathrm{C}$ and $\mathrm{B}$ showed a rather indefinite pattern with metabolites of each class increased or decreased in either group. At $28 \mathrm{~d}$ PP the difference was mainly characterized by an increase of acylcarnitines in metabotype B (whereas in the liver acylcarnitines were increased in metabotype
C) and most other metabolite groups being increased in metabotype $\mathrm{C}$ (contribution plots presented in a higher resolution in Supplemental Figure S7D F). The PLS-DA models for urine are displayed in Supplemental Figure S5. A detailed description of the metabolic alterations during the transition period and differences between the metabotypes is given in Part III (Schären et al., 2021). 
Table 1. Summary of effects of metabotypes on transition cow production and clinical traits ${ }^{1}$

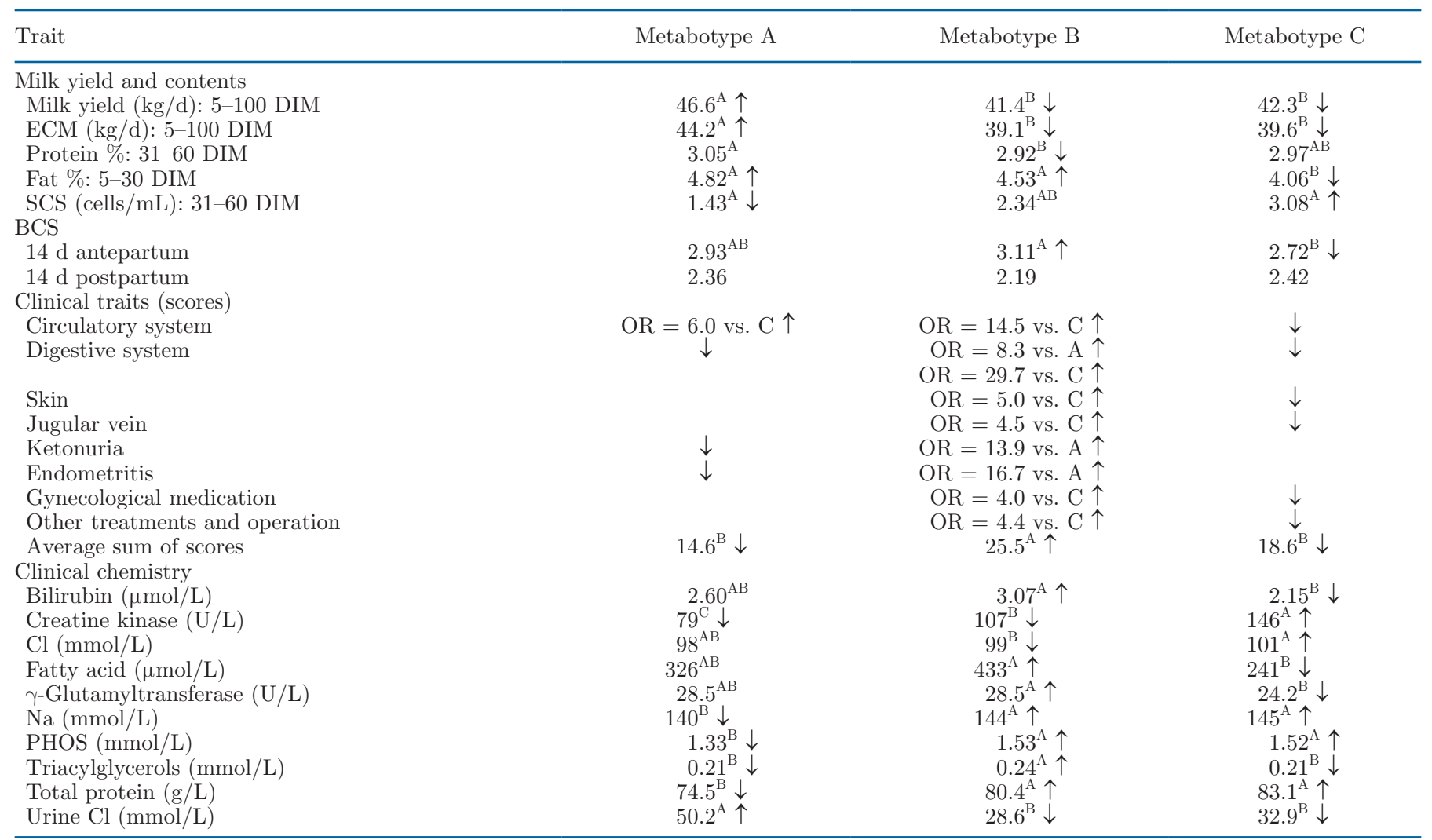

$\overline{\mathrm{A}, \mathrm{B}}$ Different letters within a row indicate significant difference $(P \leq 0.05)$ between metabotypes.

${ }^{1} \mathrm{OR}=$ odds ratio. Up and down arrows: significantly $(P \leq 0.05)$ increased or decreased compared with other metabotype(s).

\section{Animal Performance and Clinical Traits and Chemistry}

Large differences between the metabotypes were observed in all performance and clinical traits (Table 1). Especially animals calving in the period of metabotype B stood out in comparison mostly to metabotype $\mathrm{C}$ with: lower milk protein $\%$ and higher milk fat \%, higher AP and stronger peripartum decrease in BCS, higher risk for disease and treatment and with higher BILI, FA, GGT, and TAG levels. Over the course of the 3 metabotypes an increase or decrease in $\mathrm{CK}, \mathrm{Cl}, \mathrm{Na}$, PHOS, TP, and U-Cl was observed.

In comparison to the differences between the metabotypes, the treatment effects were less pronounced: the numerical highest milk yield and ECM was observed in the VER10 group, followed by CON and VER5 (Table 2) with concomitantly lower protein and fat percentages. Furthermore, no significant effects were observed in BCS and clinical traits. Regarding the clinical chemistry effects varied largely between metabotypes. In metabotype $\mathrm{A}$ and $\mathrm{B}$ several traits were affected at 7 or $28 \mathrm{~d} \mathrm{PP}$, whereas in metabotype $\mathrm{C}$ no PP effect was observed. The detailed data and elaborations are given in the text, and tables and figures in the Supplemental Files.

\section{Effect of Butaphosphan and Cyanocobalamin Treatment on Liver and Blood Metabolome}

The analysis of the complete metabolomic data set in each tissue (liver, blood, urine) revealed no clearcut treatment effect. However, when analyzing of the different sampling days, in the respective metabotypes separately, valid models, differentiating between the treatment groups, emerged (Figures 5 and 6; Supplemental Figure S6).

A treatment effect was observed in the liver in metabotype $\mathrm{C}$ at $7 \mathrm{~d} \mathrm{PP}$ (Figure 5A) and in metabotype $\mathrm{B}$ at 7 and $28 \mathrm{~d}$ PP (Figure 5B, C). The metabolic profile in metabotype $\mathrm{C}$ at $7 \mathrm{~d} \mathrm{PP}$ presented an indistinct pattern with several AA and PC increased in the VER group, and different AA, biogenic amines, acylcarnitines, (lyso)PC and sphingomyelins increased in the CON group (Figure 5A; Supplemental Figure S8A). In metabotype B a clearer pattern was observed at both PP sampling points. At $7 \mathrm{~d}$ PP several AA and a whole range of acylcarnitines and $\mathrm{PC}$ were increased 
in the VER group, whereas in the CON group mainly higher sphingomyelin concentrations were observed (Figure 5B; Supplemental Figure S8B). Three weeks later, at $28 \mathrm{~d} \mathrm{PP}$, one increased acylcarnitine $(\mathrm{C} 16-\mathrm{OH})$ mainly characterized the metabolic profile of the VER group, whereas in the CON group an increase of several lysoPC, PC, and sphingomyelins were observed (Figure 5C; Supplemental Figure S8C).

For blood samples, valid models could be constructed for metabotype $\mathrm{C}$ on $\mathrm{d} 7 \mathrm{PP}$ and for metabotype $\mathrm{A}$ and $\mathrm{B}$ on d $28 \mathrm{PP}$ The treatment effect in metabotype $\mathrm{C}$ on d 7 PP was characterized by a few driver variables from the group of acylcarnitines (Figure 6A; Supplemental Figure S8D). In metabotype A on d $28 \mathrm{PP}$ a rather indefinite pattern was observed. The treatment caused several acylcarnitines and $\mathrm{PC}$ to be either higher or lower, and several AA and sphingomyelins to be decreased in comparison to the control group (Figure 6B; Supplemental S8E). On d 28 PP in metabotype $\mathrm{B}$ the CON group exhibited mainly several increased acylcarnitines and the VER group increase of several AA, bioactive amines and PC (Figure 6C; Supplemental Figure S8F).

For urine samples valid models, differentiating between the VER and CON group, could only observed in metabotype B at 7 and $28 \mathrm{~d}$ PP (Supplemental Figure S6). As no annotation of the metabolites was performed due to capacity reasons, further analysis and interpretation of the urine data was not conducted (see Materials and Methods, Metabolomics analysis).

Table 2. Summary of effects of a metaphylactic treatment with butaphosphan and cyanocobalamin on transition cow production and clinical traits $^{1}$

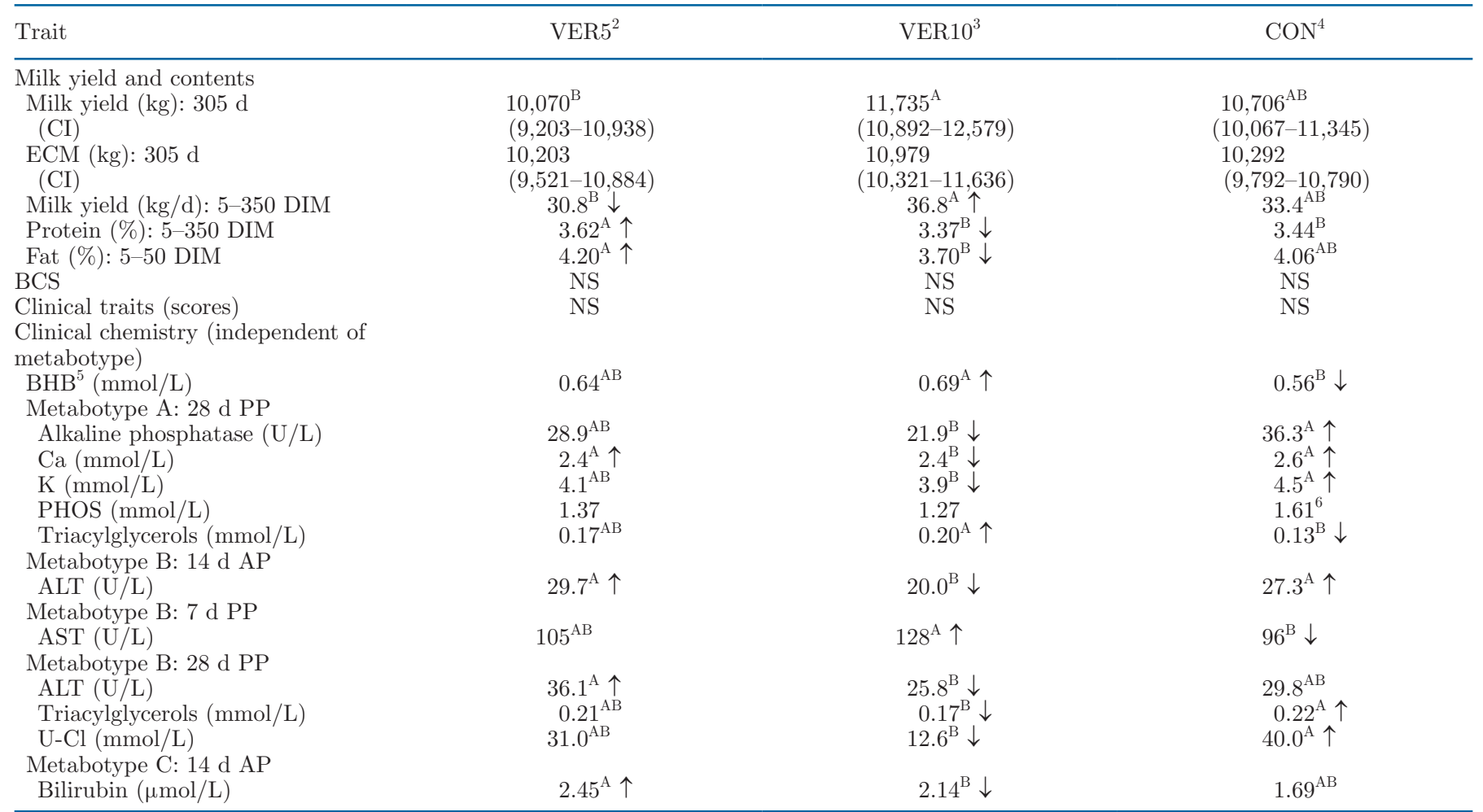

$\overline{\mathrm{A}, \mathrm{B}}$ Different letters indicate significant difference $(P \leq 0.05)$ between treatment groups.

${ }^{1} \mathrm{PP}=$ postpartum; $\mathrm{AP}=$ antepartum; ALT $=$ alanine aminotransferase; AST $=$ aspartate aminotransferase; U-Cl $=$ urine chloride. Up and down arrows: significantly $(P \leq 0.05)$ increased or decreased compared with other metabotype(s).

${ }^{2}$ VER5 = treatment group given $10 \%$ butaphosphan and $0.005 \%$ cyanocobalamin (Bayer Animal Health GmbH) with the recommended dose (as registered in Germany) of $5 \mathrm{~mL} / 100 \mathrm{~kg}$ of $\mathrm{BW}(\mathrm{n}=20$, parity: $4.2 \pm 2.0$, mean $\pm \mathrm{SD})$.

${ }^{3}$ VER $10=$ treatment group given $10 \%$ butaphosphan and $0.005 \%$ cyanocobalamin (Bayer Animal Health GmbH) with a double dose of 10 $\mathrm{mL} / 100 \mathrm{~kg}$ of $\mathrm{BW}(\mathrm{n}=20$, parity: $3.4 \pm 1.3$, mean $\pm \mathrm{SD})$.

${ }^{4} \mathrm{CON}=$ control (placebo group given 5 or $10 \mathrm{~mL}$ of $\mathrm{NaCl} 0.9 \% / 100 \mathrm{~kg}$ of $\mathrm{BW}$ (for analysis, the 2 groups were merged to one control group, $\mathrm{n}$ $=40$, parity: $4.0 \pm 1.9)$.

${ }^{5}$ Higher levels in VER10 group can mainly be accounted to higher levels at $14 \mathrm{~d}$ AP and $28 \mathrm{~d}$ PP $(0.48,0.62,0.45$ and $0.71,1.02,0.98 \mathrm{mmol} / \mathrm{L}$; VER5, VER10, CON) in metabotype B.

${ }^{6}$ VER 10 vs. CON, $P=0.125$. 


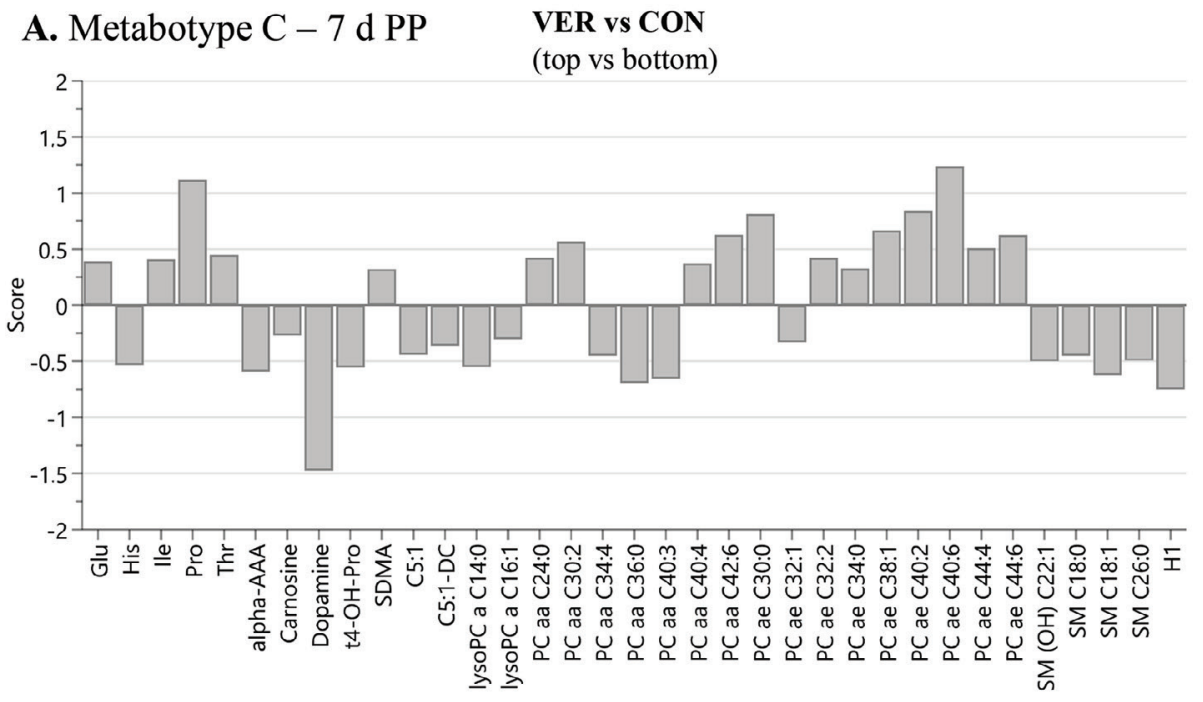

B. Metabotype B - 7 d PP

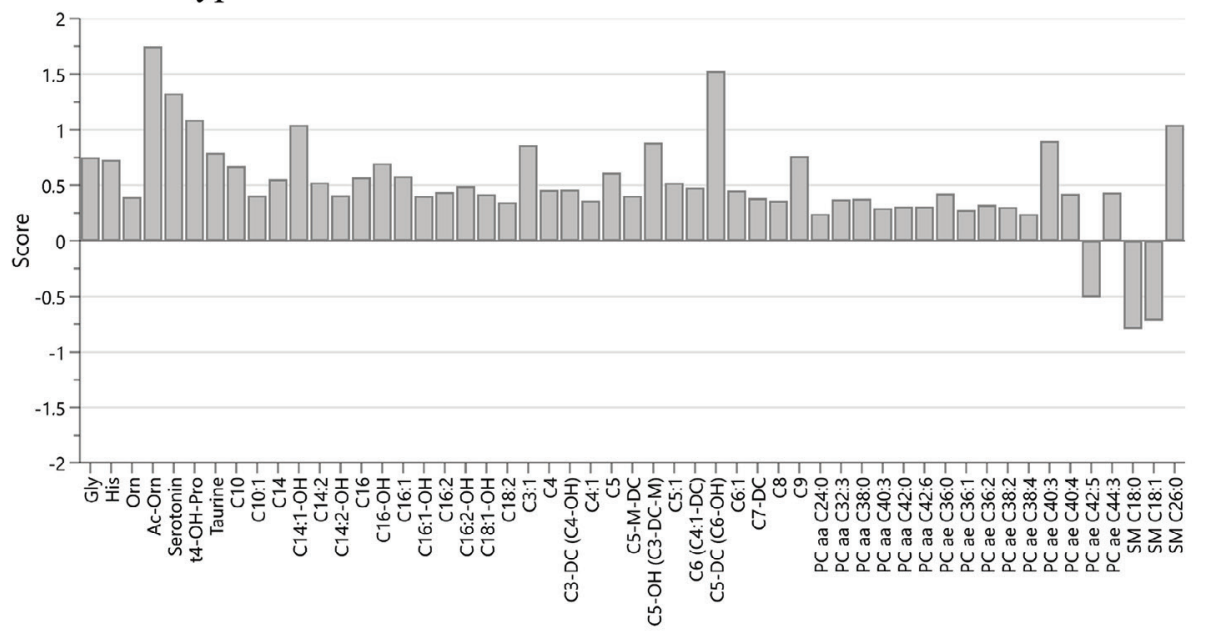

\section{Metabotype B - 28 d PP}

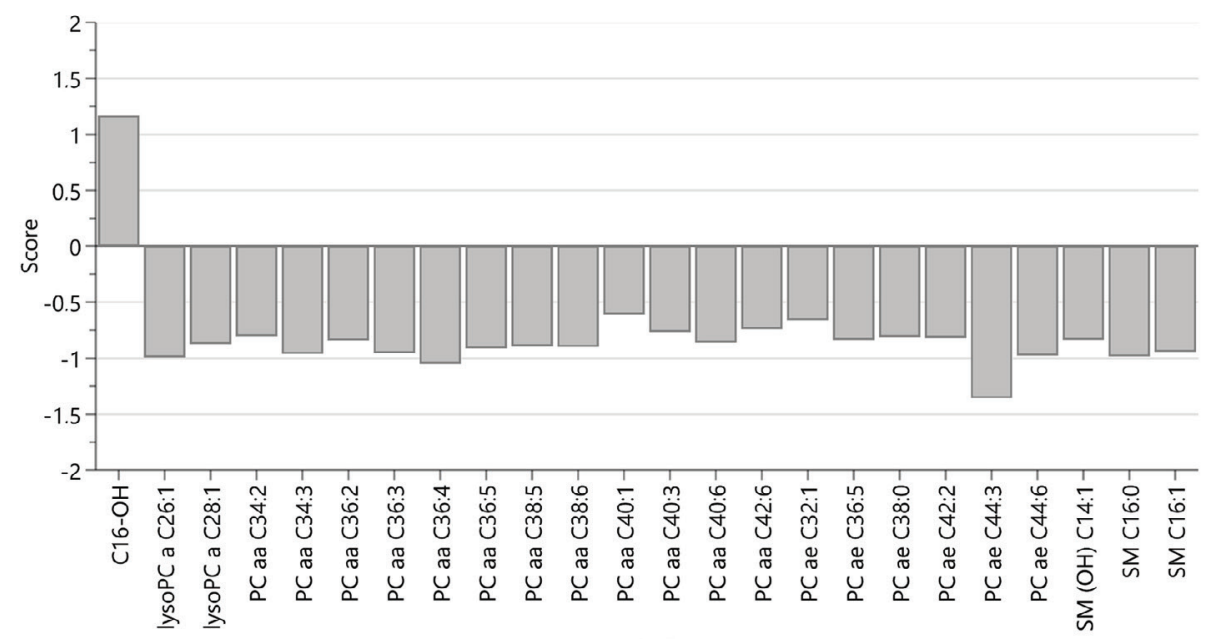

Figure 5. Contribution plots derived from partial least squares discriminant analysis models of the liver metabolome showing the driver variables of effects of a metaphylactic treatment with butaphosphan and cyanocobalamin (VER) in the different metabotypes. Only time points exhibiting a valid model, discriminating between VER and control (CON), are displayed. The vertical bars indicate the weighted difference between the data of the point and the average of the model in units of standard deviations. 
A. Metabotype $\mathrm{C}-7 \mathrm{~d}$ PP

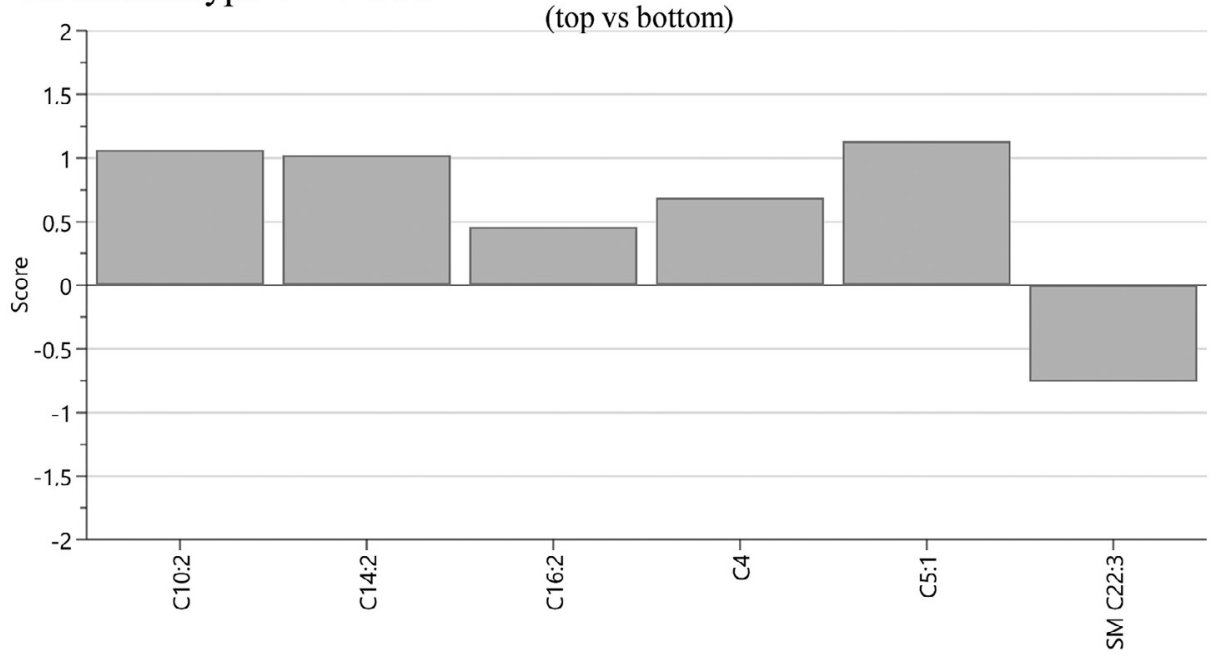

B. Metabotype A - 28 d PP

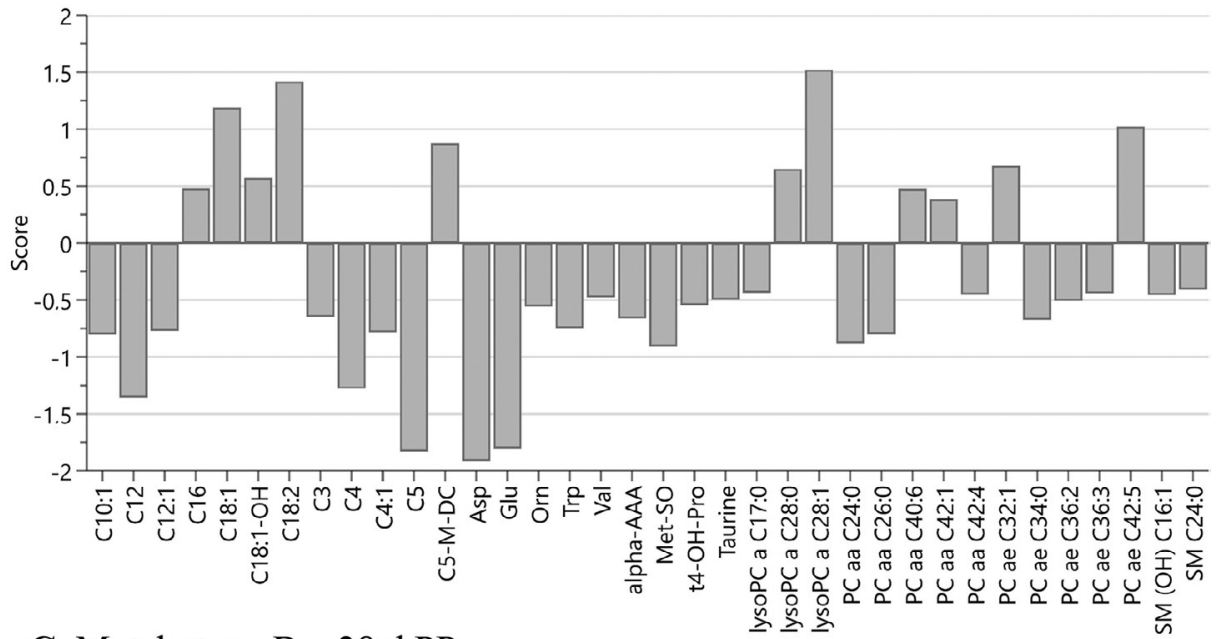

C. Metabotype B - $28 \mathrm{~d}$ PP

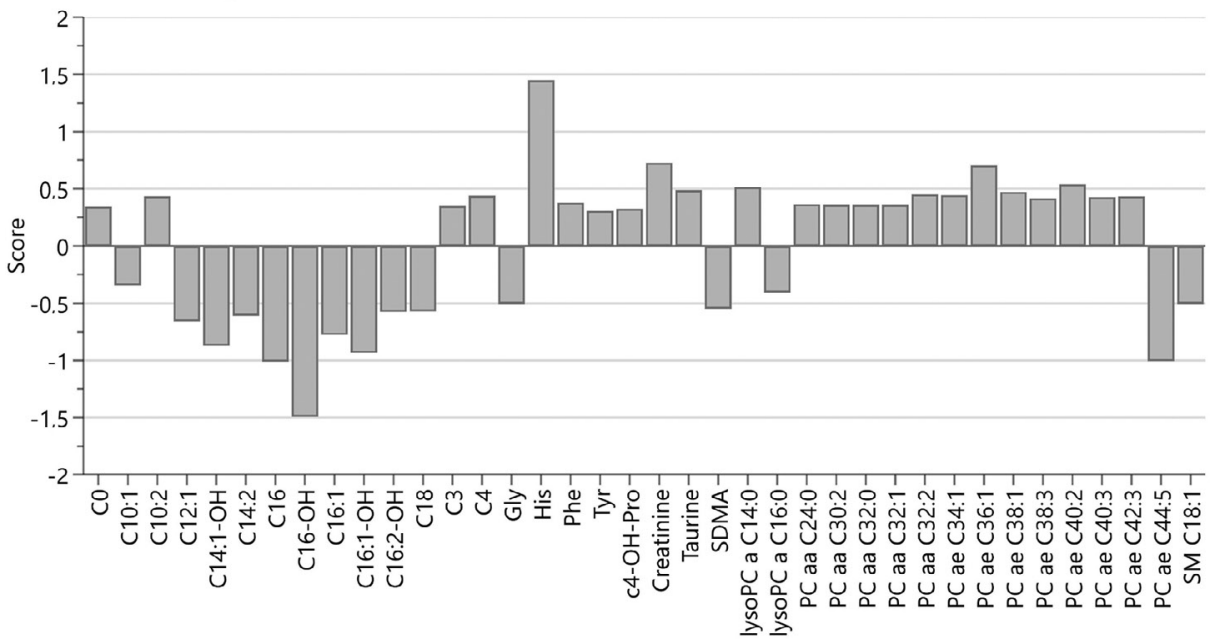

Figure 6. Contribution plots derived from partial least squares discriminant analysis models of the blood metabolome showing the driver variables of effects of a metaphylactic treatment with butaphosphan and cyanocobalamin (VER) in the different metabotypes. Only time points exhibiting a valid model, discriminating between VER and control (CON), are displayed. The vertical bars indicate the weighted difference between the data of the point and the average of the model in units of standard deviations. 
The statistical analysis, using a linear mixed model, revealed a strong influence of the metabotype and sampling day in liver and blood in line with the multivariate data analysis (details in Part III; Schären et al., 2021). For the treatment effect however, very inconclusive results were attained with no or little similarity with the multivariate analysis (described in detail in the Supplemental Files of this manuscript).

\section{DISCUSSION}

\section{Metabotype Differences}

We discovered 3 metabotypes in the PLS-DA models of the liver metabolomics data based on their metabolic alterations in the liver over the course of the transition period, which were also related to the time the animals entered the study (period/metabotypes A-C). When analyzing the information on ration and silage quality following conspicuous feature was observed: period B was characterized by several changes in silages and decreased silage quality (starting mid-March, Supplemental Table S2 and Supplemental Figure S1), indicated by an elevated ash content (99-125 g/kg DM in GS2-GS6), large DM and nutrient content variation within one silo (GS5) and most likely conservation losses due to prolonged storage (GS5: harvest year 2014). We therefore concluded that the animals in metabotype B (calving between February 7 and May 31, 2016) were exposed to a decreased grass silage quality. The definition of the metabotypes based on the results of the liver metabolomics data differ in period B by about 5 wk from alterations observed in silage quality (the decreased quality starts mid-March 2016 in silage-management data vs. beginning of February in metabolomics data). This can most likely be attributed to a delay between opening and feeding a new silo and analyzing the silage and conducting a new ration calculation.

Most pronounced differences in the different measured traits and a reasonable number of animals in each group were observed in metabotype $\mathrm{B}$ and $\mathrm{C}(\mathrm{n}=28$ and 37 ), whereas metabotype A only included 15 animals and the observed alterations in different variables were less distinct. Throughout the discussion the focus will therefore be laid on changes between metabotype $\mathrm{B}$ and $\mathrm{C}$.

\section{Production, Clinical Traits, and Clinical Chemistry}

The animals of the metabotype B group experienced a nutritional and metabolic challenge, because the described alterations in the grass silage in this period possibly led to a decrease in nutrient quality in the ration (Rotz and Muck, 1994), decrease in DMI due to a decrease palatability of the feed and a decreased intestinal passage rate (Bosch et al., 1992; Grant and Ferraretto, 2018), and an increase in the intake of toxic substances (e.g., mycotoxins, Wambacq et al., 2016). Insufficient nutrient and energy intake was the most likely cause for the substantial and fast loss of body condition in this group after calving (animals with a metabotype B exhibited a decrease of 0.92 BCS points between $14 \mathrm{~d}$ AP and $14 \mathrm{~d}$ PP, whereas this was only 0.30 BCS points in metabotype $\mathrm{C}$ animals). The animals that calved in the time period associated with metabotype $\mathrm{C}$ went through the late lactation or dry period in period $\mathrm{B}$ (the period metabotype $\mathrm{B}$ animals calved), therefore not building up as many fat reserves as the animals in metabotype A and B AP and therefore exhibiting a lower initial BCS. The corresponding clinical chemistry variables confirm the increased fat mobilization in metabotype B animals (higher FA and TAG concentrations) and metabolic load in the liver (higher BILI concentrations and GGT activity). The data illustrating the difference between metabotype $\mathrm{B}$ and $\mathrm{C}$ regarding energy metabolism were further complemented by the histopathology of liver biopsies showing the highest degree of fat accumulation, hepatocyte degeneration and an interrelation with degenerative, inflammatory, fibrotic, and proliferative traits in metabotype B animals (details in Part II; Pietsch et al., 2021).

These negative alterations on the metabolic level were associated with different clinical sequelae and reflected in the different clinical traits. The higher tissue mobilization was also mirrored in the milk production data, with the metabotype $\mathrm{B}$ exhibiting higher milk fat content during the first 30 DIM (similar to Gross et al., 2011). The milk production level was however not affected (only significant difference to metabotype A), leaving room for speculation whether this can be ascribed to the genetic potential at which the highproducing dairy cow will perform, unaffected by potential metabolic limitations and clinical consequences (Ingvartsen et al., 2003; Gross et al., 2011). The shortcoming in nutrients and the battered metabolic status was however further reflected in lower milk protein content in metabotype B at 60-100 DIM [similar to Gross et al. (2011) and Schingoethe (1996)].

The data of our study are in line with several other studies showing that animals exhibiting an increased tissue mobilization PP are at a higher risk of developing ketosis and other transition cow diseases [discussed in Gordon et al. (2017a) and Rollin et al. (2010), citing Rasmussen et al. (1999), Gillund et al. (2001), Hayirli et al. (2002), Hayirli and Grummer (2004)]. 


\section{Metabolomics Analysis}

These animals in metabotype B exhibited a distinct liver metabolome profile, characterized by little metabolic alterations between the $\mathrm{AP}$ and the $\mathrm{PP}$ status. Opposed to this observation, in metabotype $\mathrm{C}$ a whole range of metabolites increased after calving. We interpret the latter as the necessary metabolic adaptation to the physiological PP NEB and tissue mobilization, whereas the profile observed in the metabotype B most likely stands for the failure of adaptation. In blood metabolome profiles, the 3 metabotypes could also be identified, but the differences in the profiles were not as pronounced as in the liver and involved different metabolites. However, in both cases we identified acylcarnitines as a major indicative metabolite group (more details given in Part III; Schären et al., 2021). Whether these differences between the metabotypes can fully assigned to the differences in lipomobilization, or other nutritional aspects [e.g., protein quality, toxic substances (see above)] play a role are not clear in this setting (details for different metabolites in Part III; Schären et al., 2021). However, the differences in metabolite profiles observed in this study were similar to what other authors have previously described for blood metabolomics data comparing dairy cows in the transition period with a higher or lower degree of fat mobilization (Humer et al., 2016; Rico et al., 2018; Ghaffari et al., 2019; Luo et al., 2019; Yang et al., 2019). Throughout the different studies especially an increase in circulating (mainly long-chain) acylcarnitines stands in connection with an increased FA load, insulin resistance and periparturient diseases. This can most likely be explained by incomplete fatty acid oxidation or/and a failed attempt to oxidize the excess of long-chain fatty acyl-CoA to $\mathrm{CO}_{2}$ through the downstream $\beta$-oxidation (TCA cycle and respiratory chain) caused by mitochondrial overload because acylcarnitines are formed when fatty acid-CoA enter the mitochondria through the carnitine shuttle (Ghaffari et al., 2019; Yang et al., 2019). Furthermore, PC are essential for the very low-density lipoprotein synthesis and therefore for the triglyceride export from the liver (Cole et al., 2012). Shifts or especially low concentrations of certain PC in blood serum have been linked to fatty liver disease in transition cows (Imhasly et al., 2014, 2015; Humer et al., 2016; Kenéz et al., 2016; Ghaffari et al., 2019). Increased lysoPC levels as well as alterations in the sphingomyelin and AA metabolism were described in all studies mentioned above, however with inconclusive observations/outcomes.

To our knowledge this study is the first to describe the metabolome profile of transition dairy cows also in liver tissue samples. In previous publications, the source of many metabolites, measured in blood in metabolomics studies, have been largely ascribed to liver metabolism (Huber et al., 2016; Ceciliani et al., 2018). In our study, the metabotypes and treatment effect were observed in blood samples as well; however, with different metabolites involved and with contrary results for some metabolite groups (e.g., acylcarnitines) compared with the liver profiles. Further research is therefore needed to identify sources (e.g., liver, fat and muscle tissue, intestinal tract) and dynamics of different metabolites and their pathways (also discussed by Yang et al., 2019). A more in-depth presentation and discussion of the metabolome profiles in the different metabotypes, matrices and their interrelations during the transition period is given in Part III (Schären et al., 2021).

\section{Effects of Butaphosphan and Cyanocobalamin}

Animal Production, Clinical Traits, and Chemistry. No influence of a BCC treatment on BCS or clinical traits was observed. In the clinical chemistry variables, however, treatment with $\mathrm{BCC}$ affected the metabotypes differently. In metabotype A, the only differences at sampling d $28 \mathrm{PP}$ were recorded for the variables alkaline phosphatase, $\mathrm{Ca}, \mathrm{K}, \mathrm{PHOS}$, and TAG (A-VER10 vs. A-CON). Except for the latter variable, this can most likely be ascribed to the higher milk production in the VER10 group. Even though no statistical significance was reached in difference in milk production level (difference in 350-d milk production between VER10 and CON: $1,029 \mathrm{~kg}, P=0.170)$ an interrelation is plausible, because this observation is in line with previous studies showing a dose-depending increase in milk production due to a metaphylactic treatment with $\mathrm{BCC}$ and a decrease in blood alkaline phosphatase, Ca, and PHOS levels in high-producing animals (Kronfeld et al., 1982; Fürll et al., 2010; Rollin et al., 2010; Kreipe et al., 2011). Fürll et al. (2010) and Kreipe et al. (2011) discussed that that the additional PHOS originating from butaphosphan is directly drained to the increased milk production.

In the animals that calved in metabotype B treatment effects included higher AST levels at $7 \mathrm{~d}$ PP and lower TAG and U-Cl concentrations at $28 \mathrm{~d}$ PP in the B-VER10 group. We suggest that the first (AST) and latter (U-Cl) can again be mainly ascribed to the possible higher production level and therefore metabolic turnover [as described in Stojević et al. (2005); Cozzi et al. (2011); Jóźwik et al. (2012)] and excretion of Cl via milk (as described in Shalit et al., 1991) of the animals. We interpret the lower TAG concentrations as a beneficial effect on lipid metabolism, because animals in this metabotype (metabotype B) generally exhibited signifi- 
cantly higher TAG levels compared with animals in the metabotype C. Little can be found in the literature on influences on and significance of low or high TAG levels in blood. What is however repeatedly described is a decrease in blood TAG levels from AP to PP and higher TAG levels in animals exhibiting a higher degree of PP lipolysis (Piccione et al., 2012; Samanc et al., 2015). This also points toward, that a decrease in blood TAG levels PP indicates a higher metabolic capacity and may be therefore evaluated positively. Reynolds et al. (2003) discuss differences in liver TAG removal and release at different $\mathrm{AP}$ and $\mathrm{PP}$ time points depending on the nutritional and metabolic status (e.g., fasting vs. nonfasting), stating that interrelations are not elucidated. This may also explain the difference in treatment effect on TAG in our case, where an increase in TAG was observed in metabotype A (A-VER10) and a decrease in metabotype B (B-VER10) after BCC administration. The significant lower ALT levels in BVER10 compared with VER5 animals at $28 \mathrm{~d}$ PP can most likely be ascribed to general differences between these 2 groups, because ALT levels already differed AP. In the animals calving in metabotype $\mathrm{C}$, no significant $\mathrm{PP}$ treatment effects were observed in regard to the clinical chemistry variables.

In contrast to many studies (Fürll et al., 2006; Cuteri et al., 2008; Fürll et al., 2010; Rollin et al., 2010; Pereira et al., 2013; Nuber et al., 2016; Gordon et al., 2017b; Şahal et al., 2017) the BCC treatment did not cause a decrease in serum BHB and FA concentrations in our study. However, also Kreipe et al. (2011) and Tabeleão et al. (2017) recorded no effect on BHB or FA. Kreipe et al. (2011) argued that effects may be more obvious in dairy cows that suffer from high metabolic load in early lactation. In a similar study by the same group published in 2016, a decreasing effect of BCC on plasma BHB and FA concentrations in lactating cows with subclinical ketosis (Nuber et al., 2016) was observed, confirming their own hypothesis. Also, other studies discuss the possible variable effect of a $\mathrm{BCC}$ treatment depending on the clinical states of the animals studied and dosages and sampling time points applied (Rollin et al., 2010; Gordon et al., 2017a,b). In this train of thoughts Gordon et al. (2017a,b) postulated that BCC treatment may only exhibit beneficial effects in animals with concurrently high BHB and low blood glucose levels $(<2.2 \mathrm{mmol} / \mathrm{L})$. As we have not assessed $\mathrm{PP}$ glucose and $\mathrm{BHB}$ levels before treatment the reason for no observed difference between treatment groups on the level of FA and BHB concentrations remains speculative in this respect.

The concept, that the effect of a BCC treatment is depending on the metabolic state of the animal at the time of application, was also observed in our data when comparing the effects in the different metabotypes. These results are in line with the hypothesis that dairy cows may exhibit a cyanocobalamin and PHOS deficiency in the peripartum period (Kincaid and Socha, 2007; Grünberg et al., 2009), which is most likely exacerbated under unfavorable nutritional, metabolic, and immunological circumstances (Girard and Matte, 2005; Fürll et al., 2010).

Metabolomics Analysis. The alterations in the metabolic profiles observed after treatment with BCC differed between the metabotypes. In the liver only in metabotype B a clear metabolite pattern emerged at both PP sampling points after treatment. On d 7 PP the treatment effect involved an increase of acylcarnitines and PC. As described above, metabotype C was characterized by higher levels of acylcarnitines PP and concomitantly a better health status throughout the transition period. We therefore conclude that the treatment with $\mathrm{BCC}$ altered the metabolic profile of the animals in the "risk group" (metabotype B) to a more favorable metabolic pattern. The increase in acylcarnitines most likely indicates a more efficient influx and oxidation of FA into mitochondria and thereby an increase in energy supply, whereas the increase in PC indicates a more efficient triglyceride export in the liver (Ghaffari et al., 2019). This is in line with studies showing a positive interference with the glucose metabolism of $\mathrm{BCC}$ and its presumed mode of action (influence on TCA cycle, Kreipe et al. (2011)). On d 28 PP the treatment effect was characterized by completely different metabolites. In the VER group only one long-chain acylcarnitine was increased, with decreased levels of lysoPC, PC, and sphingomyelins compared with the CON group. Several studies associate an increase of lysoPC and sphingomyelins as a sign of an inflammatory response or unfavorable metabolic status, also referencing studies from humans and other animal species (Hailemariam et al., 2014a,b; Imhasly et al., 2014; Rico et al., 2015, 2018; Kenéz et al., 2016; Ghaffari et al., 2019).

The blood metabolomics data also showed different treatment effects depending on metabotypes and sampling days. In metabotype $\mathrm{C}$ the treatment caused an increase in the whole range of metabolites on $\mathrm{d} 7 \mathrm{PP}$ However, on d 28 PP no significant treatment effect was observed. Because on clinical level no treatment effects were observed in this period, the effects were only observed at d $7 \mathrm{PP}$ and the profile is not comparable to one of the metabotypes, a definite interpretation is hampered. The same accounts for the treatment effect in metabotype A, exhibiting a very indefinite pattern, with only a few metabolites involved and a low number of animals included. In metabotype B a similar effect is observed in the blood metabolite profile as in the 
liver metabolomics data. Translating the metabolic profiles of the metabotypes onto the treatment effect, an increase of favorable and especially a decrease in unfavorable metabolites is observed in the VER animals (comparable to the metabolite profile of metabotype $\mathrm{C})$. This includes higher acylcarnitine levels in the $\mathrm{CON}$ animals, and an increase in $\mathrm{AA}$ and $\mathrm{PC}$ in the VER animals.

These results show that the interpretation of metabolomics results in transition dairy cow trials are challenging (Goldansaz et al., 2017). Various studies have investigated peripartal blood serum and milk proteome, metabolome, and lipidome of transition dairy cows, in relation to energy metabolism (e.g., ketosis, fatty liver, lipomobilization), in the last 5 to $10 \mathrm{yr}$ [partially reviewed in Ceciliani et al. (2018)]. The studies have identified different metabolites throughout the whole metabolomics panel (e.g., AA, acylcarnitines, PC, sphingomyelins) as possible (predictive) markers. Thus, a large heterogeneity in the results across the studies is observed.

An important factor which makes interpretation a difficult task is that the increase or decrease of a certain metabolite can be caused by different metabolic processes, and therefore needs to be interpreted differently depending on the circumstances the analysis has been made in. An intuitive example of this is AA metabolism: an increase in certain AA may be observed under an increase or higher milk production, but also as an indicator of body tissue catabolism, and is further influenced by the dietary AA profile, liver gluconeogenesis and gastrointestinal absorption (Foldager et al. (1980), discussed in Zhou et al. (2016)). This example leads to the second obstacle when interpreting metabolomics data. Different metabolic processes in different organs may be overlapping, leaving an interpretation extremely difficult (Ametaj, 2015). Also, the implication and functional relevance of an increase or decrease of many metabolites are often not fully elucidated (Goldansaz et al., 2017) and comparison between species has to been seen critically (Dietschy et al., 1993; Lin, 1998; Andes and Craig, 2002; Ball et al., 2007). These 3 aspects are of special relevance in dairy cow research. Transition cow physiology is characterized by massive and continuous alterations in different metabolic and immunological aspects with different preconditioning factors playing a role [e.g., body condition, environmental factors, cow characteristics (e.g., age, breed, personal disease history); Peeler et al. (1994), Roche et al. (2013), Randall et al., (2018)]. Additionally, the usage of different laboratory analysis methods, hampers the comparison between studies. Therefore, we mainly compared our results to studies using similar analysis techniques (Goldansaz et al., 2017; Li et al., 2017). These aspects are emphasized even more when comparing the multivariate with the univariate statistical analysis (linear mixed model). Especially at the height of the treatment effect no clear similarity in results was attained and it was not possible to map distinct effects or patterns. Traditional statistics may not be appropriate to describe such complex interactions as observed in our trial and in metabolomics data. Due to these different reasons/aspects we abstained from describing effects on single metabolite level concerning the treatment effect.

\section{General Aspects and Limitations}

The treatment protocols were chosen according to the literature, which showed a dose-dependent effect (Fürll et al., 2010). This was also confirmed in our data, with substantial treatment effects on phenotypical traits only observed in the VER10 group. For metabolomics data valid models confirming the treatment effect could be built only when combining the VER5 and VER10 groups, confirming the difficulties described above in the analysis and interpretation of metabolomics data. The sampling time points $(7,28 \mathrm{~d}$ PP) were chosen relative to the calving and treatment following the literature (Fürll et al., 2010; Kreipe et al., 2011; Nuber et al., 2016) and to attain an impression between the immediate and prolonged PP metabolic effect of a BCC treatment. Further on, our data exhibited substantial differences in treatment effects between the 2 PP time points, indicating a transient or continuous alteration in the metabolic status of the animal in this time span. It is therefore highly likely that slightly different metabolic patterns or treatment effects would have been observed, if samples would have been taken at other time points. It is possible that the optimal moment, where the maximal treatment effect would have been observed was not captured. This also accounts for the milk production data. Because the trial was performed on a commercial dairy farm, we had to rely on the monthly milk control data, which was likely too infrequent for evaluating milk production and composition during the time of the trial itself. The practical setting of the trial also made it impossible to estimate DMI. Especially in respect to the possible effects of the decreased grass silage quality DMI data would have provided additional valuable information to put the observed metabolic alterations into context. Even though our coincidental finding of this interrelation with and likely large influence of the grass silage quality on the liver metabolome has revealed new insights in dairy cow liver and nutritional physiology it also emphasized that in future studies ration composition and detailed description of the feed quality should not only be part 
of the retrospective trial description but should be planned, anticipated and monitored very precisely. Furthermore, it also constitutes a limitation of this study because this strong influence of the ration composition possibly prevents or complicates the identification of other unrevealed dynamics in and differences between cows regarding PP metabolic adaptations.

Furthermore, the prolongation of the treatment protocol with additional BCC treatments in the first weeks $\mathrm{PP}$ should be investigated, in regard to the alterations in the treatment effect between 7 and $28 \mathrm{~d}$ PP in the liver metabolomics data (our data show an increase in acylcarnitines in the metabotype $\mathrm{C}$ at both time points, whereas the BCC treatment only caused an increase at 7 d PP).

As extensively discussed in the sections above, the treatment effects with BCC are substantially dependent on the metabolic state of the animal at the time of application. Our data as well as the literature point toward a more marked effect in what can be described as "metabolically challenged" animals. The multiple examinations and samplings (blood and urine samples, and liver biopsies) conducted throughout this trial constitute multiple stressors (Oxender et al., 1971; Hemsworth and Barnett, 2000). When comparing the production data of the 80 animals included in the trial to the 206 comparable animals in the herd (HERD) we observed a moderate decrease in milk production in the first 50 DIM in the trial animals (40.7 vs. $42.3 \mathrm{~kg}$, $P=0.066$; unpublished data), with mainly the VER5 animals contributing to this difference. Our study setup does not allow the estimation of the stand-alone BCC effect. Even though several studies have shown the production increasing effect of BCC (Girard and Matte, 2005; Preynat et al., 2009; Pereira et al., 2013), future trials with such intensive protocols should include a treatment group of which only production data (milk yield and components, and BCS) are recorded.

\section{CONCLUSIONS}

We were able to identify animals which were at risk or metabolically challenged based on their liver metabolome profile (metabotype) during the transition period. These metabolic alterations were already present AP. These animals exhibited only small differences between the AP and PP state, suggesting that the observed metabolic profiles were indicative of failure of the liver to adapt to the PP state of tissue mobilization. For the metaphylactic treatment with BCC a dose-dependent effect was confirmed, depending on the metabolic status (metabotype) of the animals. On the level of the liver and blood metabolome alterations toward a more beneficial metabolic profile were ob- served in the "metabolically challenged animals." The results support the application of an indication-based metaphylactic treatment with BCC. Nevertheless, further studies are needed, to investigate the effect of BCC and other metaphylactic treatments including different metabolic and environmental conditions.

\section{ACKNOWLEDGMENTS}

The authors want to thank the management and employees of Wirtschaftshof Sachsenland Standort Bräunsdorf for their support throughout the trials period and beyond. Their daily dedication to their cows and local milk and meat production is deeply acknowledged. Many thanks go to the whole team of the Clinical for Ruminants and Swine in Leipzig, who have supported the doctoral students and assistants in the planning and conduction of the trial, and to the laboratory team of the Bayer Pharmaceuticals, Research and Development unit in Berlin. Furthermore, we thank Bayer Animal Health GmbH and ESAOTE Biomedica Deutschland $\mathrm{GmbH}$ for the financial support. Special thanks go to Benno Waurich [Lehr- und Versuchsanstalt für Tierzucht und Tierhaltung (LVAT) e.V., Groß Kreutz, Germany] for his professional support in data exportation from the herdmanagement software and last-minute troubleshooting. The authors have not stated any conflicts of interest.

\section{REFERENCES}

Ali, T. E., and L. R. Schaeffer. 1987. Accounting for covariances among test day milk yields in dairy cows. Can. J. Anim. Sci. 67:637-644. https://doi.org/10.4141/cjas87-067.

Ametaj, B. N. 2015. A systems veterinary approach in understanding transition cow diseases: metabolomics. Pages 78-84 in Proc. 4th International Symposium on Dairy Cow Nutrition and Milk Quality, Beijing. Institute of Animal Sciences, Chinese Academy of Agricultural Sciences.

Andes, D., and W. A. Craig. 2002. Animal model pharmacokinetics and pharmacodynamics: A critical review. Int. J. Antimicrob. Agents 19:261-268. https://doi.org/10.1016/S0924-8579(02)00022 -5 .

Ball, R. O., K. L. Urschel, and P. B. Pencharz. 2007. Nutritional consequences of interspecies differences in arginine and lysine metabolism. J. Nutr. 137:1626S-1641S. https://doi.org/10.1093/jn/ 137.6.1626S.

Bobe, G., J. W. Young, and D. C. Beitz. 2004. Invited review: Pathology, etiology, prevention, and treatment of fatty liver in dairy cows. J. Dairy Sci. 87:3105-3124. https://doi.org/10.3168/jds .S0022-0302(04)73446-3.

Bosch, M. W., S. C. W. Lammers-Wienhoven, G. A. Bangma, H. Boer, and P. W. M. Van Adrichem. 1992. Influence of stage of maturity of grass silages on digestion processes in dairy cows. 2. Rumen contents, passage rates, distribution of rumen and faecal particles and mastication activity. Livest. Prod. Sci. 32:265-281. https://doi .org/10.1016/S0301-6226(12)80006-6.

Ceciliani, F., C. Lecchi, C. Urh, and H. Sauerwein. 2018. Proteomics and metabolomics characterizing the pathophysiology of adaptive reactions to the metabolic challenges during the transition from 
late pregnancy to early lactation in dairy cows. J. Proteomics 178:92-106. https://doi.org/10.1016/j.jprot.2017.10.010.

Cole, L. K., J. E. Vance, and D. E. Vance. 2012. Phosphatidylcholine biosynthesis and lipoprotein metabolism. Biochim. Biophys. Acta 1821:754-761. https://doi.org/10.1016/j.bbalip.2011.09.009.

Cozzi, G., L. Ravarotto, F. Gottardo, A. Stefani, B. Contiero, L. Moro, M. Brscic, and P. Dalvit. 2011. Reference values for blood parameters in Holstein dairy cows: Effects of parity, stage of lactation, and season of production. J. Dairy Sci. 94:3895-3901. https://doi .org/10.3168/jds.2010-3687.

Cuteri, V., L. Nisoli, A. R. Attili, A. R. Tejeda, S. Preziuso, and A. Fruganti. 2008. Clinical field evaluation of a butafosfan+ vitamin B12 compound (Phosphorum B12/Catosal) in the treatment of subclinical ketosis in dairy cows. Magyar Allatorvosok Lapja 130(Suppl II):16-17.

Dietschy, J. M., S. D. Turley, and D. K. Spady. 1993. Role of liver in the maintenance of cholesterol and low density lipoprotein homeostasis in different animal species, including humans. J. Lipid Res. 34:1637-1659. https://doi.org/10.1016/S0022-2275(20)35728-X.

Dirksen, G., H.-D. Gründer, and M. Stöber. 2012. Die Klinische Untersuchung des Rindes. Enke.

Drackley, J. K., H. M. Dann, N. Douglas, N. A. J. Guretzky, N. B. Litherland, J. P. Underwood, and J. J. Loor. 2005. Physiological and pathological adaptations in dairy cows that may increase susceptibility to periparturient diseases and disorders. Ital. J. Anim. Sci. 4:323-344. https://doi.org/10.4081/ijas.2005.323.

Drackley, J. K., T. R. Overton, and G. N. Douglas. 2001. Adaptations of glucose and long-chain fatty acid metabolism in liver of dairy cows during the periparturient period. J. Dairy Sci. 84:E100-E112. https://doi.org/10.3168/jds.S0022-0302(01)70204-4.

Edmonson, A. J., I. J. Lean, L. D. Weaver, T. Farver, and G. Webster. 1989. A body condition scoring chart for Holstein dairy cows. J. Dairy Sci. 72:68-78. https://doi.org/10.3168/jds.S0022 -0302(89)79081-0.

Foldager, J., J. T. Huber, and W. G. Bergen. 1980. Factors affecting amino acids in blood of dairy cows. J. Dairy Sci. 63:396-404. https: //doi.org/10.3168/jds.S0022-0302(80)82946-8.

Fürll, M., A. Deniz, B. Westphal, C. Illing, and P. D. Constable. 2010. Effect of multiple intravenous injections of butaphosphan and cyanocobalamin on the metabolism of periparturient dairy cows. J. Dairy Sci. 93:4155-4164. https://doi.org/10.3168/jds.2009-2914.

Fürll, M., T. Wittek, S. Gengenbach, and B. Schmidt. 2006. Effekte einer präoperativen Applikation von Butafosfan und Cyano-cobalamin auf Rekonvaleszenz, klinisch-chemische Parameter, antioxidativen Stoffwechsel und postoperative Labmagenentleerung bei Kühen mit Dislocatio abomasi. Tierarztl. Prax. Ausg. G Grosstiere Nutztiere 34:351-356. https://doi.org/10.1055/s-0038-1625758.

Ghaffari, M. H., A. Jahanbekam, H. Sadri, K. Schuh, G. Dusel, C. Prehn, J. Adamski, C. Koch, and H. Sauerwein. 2019. Metabolomics meets machine learning: Longitudinal metabolite profiling in serum of normal versus overconditioned cows and pathway analysis. J. Dairy Sci. 102:11561-11585. https://doi.org/10.3168/ jds.2019-17114.

Gillund, P., O. Reksen, Y. T. Gröhn, and K. Karlberg. 2001. Body condition related to ketosis and reproductive performance in Norwegian dairy cows. J. Dairy Sci. 84:1390-1396. https://doi.org/10 .3168/jds.S0022-0302(01)70170-1.

Girard, C. L., and J. J. Matte. 2005. Effects of intramuscular injections of vitamin B12 on lactation performance of dairy cows fed dietary supplements of folic acid and rumen-protected methionine. J. Dairy Sci. 88:671-676. https://doi.org/10.3168/jds.S0022 $-0302(05) 72731-4$.

Gohlke, A., C. J. Ingelmann, G. Nürnberg, J. M. Weitzel, H. M. Hammon, S. Görs, A. Starke, S. Wolffram, and C. C. Metges. 2013. Influence of 4-week intraduodenal supplementation of quercetin on performance, glucose metabolism, and mRNA abundance of genes related to glucose metabolism and antioxidative status in dairy cows. J. Dairy Sci. 96:6986-7000. https://doi.org/10.3168/ jds.2013-6852.

Goldansaz, S. A., A. C. Guo, T. Sajed, M. A. Steele, G. S. Plastow, and D. S. Wishart. 2017. Livestock metabolomics and the livestock metabolome: A systematic review. PLoS One 12:e0177675. https:/ /doi.org/10.1371/journal.pone.0177675.

Gordon, J. L., T. F. Duffield, T. H. Herdt, D. F. Kelton, L. Neuder, and S. J. LeBlanc. 2017a. Effects of a combination butaphosphan and cyanocobalamin product and insulin on ketosis resolution and milk production. J. Dairy Sci. 100:2954-2966. https://doi.org/10 $.3168 /$ jds.2016-11925.

Gordon, J. L., S. J. LeBlanc, D. F. Kelton, T. H. Herdt, L. Neuder, and T. F. Duffield. 2017b. Randomized clinical field trial on the effects of butaphosphan-cyanocobalamin and propylene glycol on ketosis resolution and milk production. J. Dairy Sci. 100:3912-3921. https://doi.org/10.3168/jds.2016-11926.

Grant, R. J., and L. F. Ferraretto. 2018. Silage review: Silage feeding management: Silage characteristics and dairy cow feeding behavior. J. Dairy Sci. 101:4111-4121. https://doi.org/10.3168/jds.2017 -13729 .

Gross, J., H. A. van Dorland, R. M. Bruckmaier, and F. J. Schwarz. 2011. Performance and metabolic profile of dairy cows during a lactational and deliberately induced negative energy balance with subsequent realimentation. J. Dairy Sci. 94:1820-1830. https://doi .org/10.3168/jds.2010-3707.

Grummer, R. R. 1993. Etiology of lipid-related metabolic disorders in periparturient dairy cows. J. Dairy Sci. 76:3882-3896. https://doi .org/10.3168/jds.S0022-0302(93)77729-2.

Grummer, R. R. 2008. Nutritional and management strategies for the prevention of fatty liver in dairy cattle. Vet. J. 176:10-20. https:/ /doi.org/10.1016/j.tvjl.2007.12.033.

Grünberg, W., R. Staufenbiel, P. D. Constable, H. M. Dann, D. E. Morin, and J. K. Drackley. 2009. Liver phosphorus content in Holstein-Friesian cows during the transition period. J. Dairy Sci. 92:2106-2117. https://doi.org/10.3168/jds.2008-1897.

Hahn, G. L. 1999. Dynamic responses of cattle to thermal heat loads. J. Anim. Sci. 77(suppl_2):10-20. https://doi.org/10.2527/1997 .77suppl_210x.

Hailemariam, D., R. Mandal, F. Saleem, S. M. Dunn, D. S. Wishart, and B. N. Ametaj. 2014a. Identification of predictive biomarkers of disease state in transition dairy cows. J. Dairy Sci. 97:2680-2693. https://doi.org/10.3168/jds.2013-6803.

Hailemariam, D., R. Mandal, F. Saleem, S. M. Dunn, D. S. Wishart, and B. N. Ametaj. 2014b. Metabolomics approach reveals altered plasma amino acid and sphingolipid profiles associated with patholological state in transition dairy cows. Curr. Metabolomics 2:184-195. https://doi.org/10.2174/2213235X03666141216201446.

Hayirli, A., and R. R. Grummer. 2004. Factors affecting dry matter intake prepartum in relationship to etiology of peripartum lipidrelated metabolic disorders: A review. Can. J. Anim. Sci. 84:337347. https://doi.org/10.4141/A03-122.

Hayirli, A., R. R. Grummer, E. V. Nordheim, and P. M. Crump. 2002. Animal and dietary factors affecting feed intake during the prefresh transition period in Holsteins. J. Dairy Sci. 85:3430-3443. https://doi.org/10.3168/jds.S0022-0302(02)74431-7.

Hemsworth, P. H., and J. L. Barnett. 2000. Human-animal interactions and animal stress. Pages 309-315 in The Biology of Animal Stress - The Biology of Animal Stress: Basic Principles and Implications for Animal Welfare. G. P. Moberg and J. A. Mench, ed. CABI.

Huber, K., S. Dänicke, J. Rehage, H. Sauerwein, W. Otto, U. RolleKampczyk, and M. von Bergen. 2016. Metabotypes with properly functioning mitochondria and anti-inflammation predict extended productive life span in dairy cows. Sci. Rep. 6:24642. https://doi .org/10.1038/srep24642.

Humer, E., S. Aditya, and Q. Zebeli. 2018. Innate immunity and metabolomic responses in dairy cows challenged intramammarily with lipopolysaccharide after subacute ruminal acidosis. Animal 12:2551-2560. https://doi.org/10.1017/S1751731118000411.

Humer, E., A. Khol-Parisini, B. U. Metzler-Zebeli, L. Gruber, and Q. Zebeli. 2016. Alterations of the lipid metabolome in dairy cows experiencing excessive lipolysis early postpartum. PLoS One 11:e0158633. https://doi.org/10.1371/journal.pone.0158633.

Imhasly, S., C. Bieli, H. Naegeli, L. Nystrom, M. Ruetten, and C. Gerspach. 2015. Blood plasma lipidome profile of dairy cows during 
the transition period. BMC Vet. Res. 11:252. https://doi.org/10 $.1186 / \mathrm{s} 12917-015-0565-8$.

Imhasly, S., H. Naegeli, S. Baumann, M. von Bergen, A. Luch, H. Jungnickel, S. Potratz, and C. Gerspach. 2014. Metabolomic biomarkers correlating with hepatic lipidosis in dairy cows. BMC Vet. Res. 10:122. https://doi.org/10.1186/1746-6148-10-122.

Ingvartsen, K. L. 2006. Feeding- and management-related diseases in the transition cow: Physiological adaptations around calving and strategies to reduce feeding-related diseases. Anim. Feed Sci. Technol. 126:175-213. https://doi.org/10.1016/j.anifeedsci.2005 .08 .003 .

Ingvartsen, K. L., R. J. Dewhurst, and N. C. Friggens. 2003. On the relationship between lactational performance and health: Is it yield or metabolic imbalance that cause production diseases in dairy cattle? A position paper. Livest. Prod. Sci. 83:277-308. https:// doi.org/10.1016/S0301-6226(03)00110-6.

Jóźwik, A., N. Strzałkowska, E. Bagnicka, W. Grzybek, J. Krzyżewski, E. Polawska, A. Kołataj, and J. O. Horbańczuk. 2012. Relationship between milk yield, stage of lactation, and some blood serum metabolic parameters of dairy cows. Czech J. Anim. Sci. 57:353360. https://doi.org/10.17221/6270-CJAS.

Kenéz, Á., S. Dänicke, U. Rolle-Kampczyk, M. von Bergen, and K. Huber. 2016. A metabolomics approach to characterize phenotypes of metabolic transition from late pregnancy to early lactation in dairy cows. Metabolomics 12:165. https://doi.org/10.1007/s11306 -016-1112-8.

Kenward, M. G., and J. H. Roger. 1997. Small sample inference for fixed effects from restricted maximum likelihood. Biometrics 53:983-997. https://doi.org/10.2307/2533558.[REMOVED HYPERLINK FIELD]

Kenward, M. G., and J. H. Roger. 2009. An improved approximation to the precision of fixed effects from restricted maximum likelihood. Comput. Stat. Data Anal. 53:2583-2595. https://doi.org/10 $.1016 /$ j.csda.2008.12.013.

Kincaid, R. L., and M. T. Socha. 2007. Effect of cobalt supplementation during late gestation and early lactation on milk and serum measures. J. Dairy Sci. 90:1880-1886. https://doi.org/10.3168/jds .2006-296.

Kreipe, L., A. Deniz, R. M. Bruckmaier, and H. A. van Dorland. 2011. First report about the mode of action of combined butafosfan and cyanocobalamin on hepatic metabolism in nonketotic early lactating cows. J. Dairy Sci. 94:4904-4914. https://doi.org/10.3168/jds $.2010-4080$.

Kretschmann, J., L. Scherf, M. L. Fischer, M. Kaiser, H. Müller, J. Spilke, N. Mielenz, G. Möbius, L. Bittner, I. Steinhöfel, W. Baumgartner, and A. Starke. 2020. Einfluss der thermischen Enthornung mit unterschiedlichem Schmerzmanagement auf die Gesundheit von Kälbern. Tierarztl. Prax. Ausg. G Grosstiere Nutztiere 48:318-326. https://doi.org/10.1055/a-1229-8393.

Kronfeld, D. S., S. Donoghue, R. L. Copp, F. M. Stearns, and R. H. Engle. 1982. Nutritional status of dairy cows indicated by analysis of blood. J. Dairy Sci. 65:1925-1933. https://doi.org/10.3168/jds .S0022-0302(82)82440-5.

Li, S., Q. Wang, X. Lin, X. Jin, L. Liu, C. Wang, Q. Chen, J. Liu, and H. Liu. 2017. The use of "omics" in lactation research in dairy cows. Int. J. Mol. Sci. 18:983. https://doi.org/10.3390/ijms18050983.

Lin, J. H. 1998. Applications and limitations of interspecies scaling and in vitro extrapolation in pharmacokinetics. Drug Metab. Dispos. 26:1202-1212.

Lohr, B., B. Brunner, H. Janowitz, M. Hummel, T. Seeger, I. Weber, T. Wittek, B. Schmidt, and K. Hellmann. 2006. Efficacy of Catosal for the treatment of ketosis in cows with left abomasal displacement. Tierarztl. Umsch. 61:187-190.

Luo, Z. Z., L. H. Shen, J. Jiang, Y. X. Huang, L. P. Bai, S. M. Yu, X. P. Yao, Z. H. Ren, Y. X. Yang, and S. Z. Cao. 2019. Plasma metabolite changes in dairy cows during parturition identified using untargeted metabolomics. J. Dairy Sci. 102:4639-4650. https://doi .org/10.3168/jds.2018-15601.

Mann, S., J. McArt, and A. Abuelo. 2019. Production-related metabolic disorders of cattle: Ketosis, milk fever and grass staggers. In Pract. 41:205-219. https://doi.org/10.1136/inp.13041.
Manning, A. 2019. Clinical and subclinical ketosis in dairy cattle. Livestock (Lond) 24:13-17. https://doi.org/10.12968/live.2019.24.1.13.

McCulloch, C. E., and S. R. Searle. 2001. Generalized, Linear and Mixed Models. John Wiley and Sons Inc.

Mielenz, N., J. Spilke, H. Krejcova, and L. Schüler. 2006. Statistical analysis of test-day milk yields using random regression models for the comparison of feeding groups during the lactation period. Arch. Anim. Nutr. 60:341-357. https://doi.org/10.1080/ 17450390600884435.

Mulligan, F. J., and M. L. Doherty. 2008. Production diseases of the transition cow. Vet. J. 176:3-9. https://doi.org/10.1016/j.tvjl.2007 .12 .018 .

Mulligan, F. J., L. O'Grady, D. A. Rice, and M. L. Doherty. 2006. A herd health approach to dairy cow nutrition and production diseases of the transition cow. Anim. Reprod. Sci. 96:331-353. https: //doi.org/10.1016/j.anireprosci.2006.08.011.

Nuber, U., H. A. van Dorland, and R. M. Bruckmaier. 2016. Effects of butafosfan with or without cyanocobalamin on the metabolism of early lactating cows with subclinical ketosis. J. Anim. Physiol. Anim. Nutr. (Berl.) 100:146-155. https://doi.org/10.1111/jpn .12332 .

Oxender, W. D., E. W. Askew, J. D. Benson, and R. S. Emery. 1971. Biopsy of liver, adipose tissue and mammary gland of lactating cows. J. Dairy Sci. 54:286-288. https://doi.org/10.3168/jds.S0022 $-0302(71) 85827-7$.

Palmer, C. R. 1980. "Metaphylaxis" in post-partum conditions in dairy cows with butaphosphone: A trial under South African conditions. J. S. Afr. Vet. Assoc. 51:239-242.

Peeler, E. J., M. J. Otte, and R. J. Esslemont. 1994. Recurrence odds ratios for periparturient diseases and reproductive traits of dairy cows. Br. Vet. J. 150:481-488. https://doi.org/10.1016/S0007 $-1935(05) 80201-5$.

Pereira, R. A., P. A. S. Silveira, P. Montagner, A. Schneider, E. Schmitt, V. R. Rabassa, L. F. M. Pfeifer, F. A. B. Del Pino, M. E. Pulga, and M. N. Corrêa. 2013. Effect of butaphosphan and cyanocobalamin on postpartum metabolism and milk production in dairy cows. Animal 7:1143-1147. https://doi.org/10.1017/ S1751731113000013.

Piccione, G., V. Messina, S. Marafioti, S. Casella, C. Giannetto, and F. Fazio. 2012. Changes of some haematochemical parameters in dairy cows during late gestation, post partum, lactation and dry periods. Vet. Zootech. 58:59-64.

Pietsch, F., M. Schären, T. Snedec, K. B. Theinert, A.-S. Leonhardt, A. Kaiser, F. Rachili, D. Bottcher, J. Scheinert, H.-A. Schoon, P. Wohlsein, J. Spilke, A. Haudum, W. Baumgartner, and A. Starke. 2021. Aspects of transition cow metabolomics - Part II: Histomorphologic changes in the liver parenchyma throughout the transition period, in cows with different liver metabotypes and effects of a metaphylactic butaphosphan and cyanocobalamin treatment. J. Dairy Sci. 104:9227-9244. https://doi.org/10.3168/jds.2020-19057.

Preynat, A., H. Lapierre, M. C. Thivierge, M. F. Palin, J. J. Matte, A. Desrochers, and C. L. Girard. 2009. Effects of supplements of folic acid, vitamin B12, and rumen-protected methionine on whole body metabolism of methionine and glucose in lactating dairy cows. J. Dairy Sci. 92:677-689. https://doi.org/10.3168/jds .2008-1525.

Randall, L. V, M. J. Green, L. E. Green, M. G. G. Chagunda, C. Mason, S. C. Archer, and J. N. Huxley. 2018. The contribution of previous lameness events and body condition score to the occurrence of lameness in dairy herds: A study of 2 herds. J. Dairy Sci. 101:1311-1324. https://doi.org/10.3168/jds.2017-13439.

Rasmussent, L. K., B. L. Nielsen, J. E. Pryce, T. T. Mottram, and R. F. Veerkamp. 1999. Risk factors associated with the incidence of ketosis in dairy cows. Anim. Sci. 68:379-386. https://doi.org/10 .1017/S1357729800050372.

Reents, R., J. Jamrozik, L. R. Schaeffer, and J. C. M. Dekkers. 1995. Estimation of genetic parameters for test day records of somatic cell score. J. Dairy Sci. 78:2847-2857. https://doi.org/10.3168/jds .S0022-0302(95)76915-6. 
Reid, I. M., and R. A. Collins. 1980. The pathology of post-parturient fatty liver in high-yielding dairy cows. Invest. Cell Pathol. $3: 237-249$.

Reynolds, C. K., P. C. Aikman, B. Lupoli, D. J. Humphries, and D. E. Beever. 2003. Splanchnic metabolism of dairy cows during the transition from late gestation through early lactation. J. Dairy Sci. 86:1201-1217. https://doi.org/10.3168/jds.S0022-0302(03)73704 $-7$.

Rico, J. E., V. V. R. Bandaru, J. M. Dorskind, N. J. Haughey, and J. W. McFadden. 2015. Plasma ceramides are elevated in overweight Holstein dairy cows experiencing greater lipolysis and insulin resistance during the transition from late pregnancy to early lactation. J. Dairy Sci. 98:7757-7770. https://doi.org/10.3168/jds.2015 -9519 .

Rico, J. E., Y. Zang, N. J. Haughey, A. G. Rius, and J. W. McFadden. 2018. Circulating fatty acylcarnitines are elevated in overweight periparturient dairy cows in association with sphingolipid biomarkers of insulin resistance. J. Dairy Sci. 101:812-819. https:/ /doi.org/10.3168/jds.2017-13171.

Roche, J. R. A. W. Bell, T. R. Overton, and J. J. Loor. 2013. Nutritional management of the transition cow in the 21st century-a paradigm shift in thinking. Anim. Prod. Sci. 53:1000-1023. https: //doi.org/10.1071/AN12293.

Rollin, E., R. D. Berghaus, P. Rapnicki, S. M. Godden, and M. W. Overton. 2010. The effect of injectable butaphosphan and cyanocobalamin on postpartum serum $\beta$-hydroxybutyrate, calcium, and phosphorus concentrations in dairy cattle. J. Dairy Sci. 93:978987. https://doi.org/10.3168/jds.2009-2508.

Rotz, C. A., and R. E. Muck. 1994. Changes in forage quality during harvest and storage. Pages 828-868 in Forage Quality, Evaluation, and Utilization. Crop Science Society of America.

Şahal, M., A. Deníz, R. Vural, Ş. Küplülü, I. M. Polat, E. Ç. Çolakoğlu, N. Öcal, H. C. Macun, M. Pekcan, and M. Ocak. 2017. Evaluation of the effect of different doses of butaphosphan and cyanocobalamin combination in dairy cattle with subclinical ketosis. Kafkas Univ. Vet. Fak. Derg. 23:349-356.

Samanc, H., D. Gvozdic, N. Fratric, D. Kirovski, R. Djokovic, Z. Sadojevic, and M. Cincovic. 2015. Body condition score loss, hepatic lipidosis and selected blood metabolites in Holstein cows during transition period. Anim. Sci. Pap. Rep. 33:35-47.

Schingoethe, D. J. 1996. Dietary influence on protein level in milk and milk yield in dairy cows. Anim. Feed Sci. Technol. 60:181-190. https://doi.org/10.1016/0377-8401(96)00975-3.

Schären, M., B. Riefke, M. Slopianka, M. Keck, S. Gruendemann, J. Wichard, N. Brunner, S. Klein, T. Snedec, K. B. Theinert, F. Pietsch, F. Rachidi, G. Köller, E. Bannert, J. Spilke, and A. Starke. 2021. Aspects of transition cow metabolomics-Part III: Altera- tions in the metabolome of liver and blood throughout the transition period in cows with different liver metabotypes. J. Dairy Sci. 104:9245-9262. https://doi.org/10.3168/jds/2020-19056.

Shalit, U., E. Maltz, N. Silanikove, and A. Berman. 1991. Water, sodium, potassium, and chlorine metabolism of dairy cows at the onset of lactation in hot weather. J. Dairy Sci. 74:1874-1883. https://doi .org/10.3168/jds.S0022-0302(91)78353-7.

Society of Nutrition Physiology. (Gesellschaft für Ernährung, GfE). 2001. Empfehlungen zur Energie- und Nährstoffversorgung der Milchkühe und Aufzuchtrinder; DLG-Verlags-GmbH.

Sommer, H., D. Marx, and G. Starker. 1971. Reduction of cattle fertility disorders using Catosal during metaphylaxis. Dtsch. Tierarztl. Wochenschr. 78:593-597.

Stojević, Z., J. Piršljin, S. Milinković-Tur, M. Zdelar-Tuk, and B. B. Ljubić. 2005. Activities of AST, ALT and GGT in clinically healthy dairy cows during lactation and in the dry period. Vet. Arh. 75:67-73.

Sun, L. W., H. Y. Zhang, L. Wu, S. Shu, C. Xia, C. Xu, and J. S. Zheng. 2014. (1)H-Nuclear magnetic resonance-based plasma metabolic profiling of dairy cows with clinical and subclinical ketosis. J. Dairy Sci. 97:1552-1562. https://doi.org/10.3168/jds.2013 $-6757$.

Tabeleão, V. C., R. A. Pereira, R. F. Prietsch, J. O. Feijó, C. Bondan, P. Mattei, E. Schmitt, F. A. B. del Pino, and M. N. Corrêa. 2016 Butafosfan and cyanocobalamin: Indirect effects on the recovery of the mammary gland of dairy cows after clinical mastitis. Sci. Anim. Health 4:238-254.

Tabeleão, V. C., E. Schwegler, R. A. Pereira, A. R. T. Krause, P. Montagner, J. O. Feijó, A. Schneider, E. Schmitt, C. C. Brauner, V. R. Rabassa, F. A. B. Del Pino, and M. N. Corrêa. 2017. Combined of butaphosphan and cyanocobalamin on the glucose metabolism of dairy cows after calving. Arq. Bras. Med. Vet. Zootec. 69:317-324.

Wambacq, E., I. Vanhoutte, K. Audenaert, L. De Gelder, and G. Haesaert. 2016. Occurrence, prevention and remediation of toxigenic fungi and mycotoxins in silage: A review. J. Sci. Food Agric 96:2284-2302. https://doi.org/10.1002/jsfa.7565.

Yang, Y., H. Sadri, C. Prehn, J. Adamski, J. Rehage, S. Dänicke, B. Saremi, and H. Sauerwein. 2019. Acylcarnitine profiles in serum and muscle of dairy cows receiving conjugated linoleic acids or a control fat supplement during early lactation. J. Dairy Sci. 102:754-767. https://doi.org/10.3168/jds.2018-14685.

Zhou, Z., J. J. Loor, F. Piccioli-Cappelli, F. Librandi, G. E. Lobley, and E. Trevisi. 2016. Circulating amino acids in blood plasma during the peripartal period in dairy cows with different liver functionality index. J. Dairy Sci. 99:2257-2267. https://doi.org/ $10.3168 /$ jds.2015-9805. 